\title{
Bodies and their parts: An NSM approach to semantic typology
}

\author{
Anna Wierzbicka \\ Australian National University, School of Language Studies, ACT 0200, Australia \\ Received 5 May 2006; accepted 10 July 2006
}

In memory of Uriel Weinreich, 1926-1967

\begin{abstract}
This paper puts forward, on the basis of evidence and analysis, seven general principles of conceptualization of the body, reflected in the semantic organization of the 'body and body-parts' field across languages. It supplies a large set of semantic explications of English body-part terms, and it shows how ethno-anatomies can be described and compared through the use of the natural semantic metalanguage (NSM). It also returns to the controversial issue of the body-centric character of language and cognition. The paper is, to some extent, a reaction to the Special Issue on "Parts of the body: cross-linguistic categorization" (Language Sciences 28:2-3). One of its goals is to vindicate well-established semantic universals such as body and part, which the Special Issue questions on the basis of raw data, discussed (as is it is argued) in a theoretical vacuum. More generally, the paper argues that semantic typology requires a semantic methodology and it shows what a theoreticallyanchored semantic typology can look like.

(c) 2006 Elsevier Ltd. All rights reserved.
\end{abstract}

Keywords: Body-part terms; Language universals; Linguistic typology; Lexical semantics; Cross-linguistic semantics; NSM; Anthropocentrism and bodycentrism

E-mail address: anna.wierzbicka@anu.edu.au 


\section{Introduction: reopening the debate ${ }^{1}$}

The Introduction to the recent Special Issue of Language Sciences (Majid, Enfield and van Staden (Eds.), 2006) entitled "Parts of the body: cross-linguistic categorization" states that "the domain of the human body is an ideal focus for semantic typology" (Enfield et al., 2006, Abstract), and I agree. As I would argue, however, this is so not for the reasons offered by the authors of that introduction: "the domain of the human body is an ideal focus for semantic typology since the body is a physical universal and all languages have terms referring to its parts" (Enfield et al., 2006, Abstract). What does it mean that the body is a "physical universal"? Earth, water and air are also "physical universals" (they are everywhere where there are people), but they are not an ideal focus for semantic typology.

The domain of the human body is an ideal focus for semantic typology and, I would add, cognitive anthropology, because the body is, almost certainly, a conceptual, rather than "physical", universal (see Section 3), and because it is of special interest and importance to speakers. Furthermore, rigorous semantic analysis suggests that this object of unique interest and importance - the human body - is universally conceptualized in terms of "parts" (see Section 4). What matters is not that "all languages have terms referring to its parts" (Enfield et al., 2006, Abstract), but that despite a good deal of variation in the lexical details, everywhere in the world people appear to think about the human body in terms of certain parts, such as, roughly speaking, eyes, ears, nose and mouth, and head, hands, arms and legs.

According to the Special Issue on "Parts of the body", however, there are languages which have no word for 'body', no word for 'head', no word for 'hands', no word for 'eyes', no word for 'mouth', and, moreover - some articles claim - no word for 'part'.

In their introduction to the Special Issue, Enfield et al. (2006, p. 145) note: "Among proposed universals in this domain are that there will be distinct terms for 'body', 'head', 'arm', 'eyes', 'nose' and 'mouth"'. They then reject the validity of these previously proposed universals: "Several languages do not have a general term meaning 'body'. (...) There is no term meaning 'arm' in Lavukaleve, and no term meaning 'mouth' in Jahai."

In the same Special Issue, Levinson (2006, p. 222) claims that the Papuan language Yélî Dnye has "terms for upper and lower leg but no ordinary term for the leg as a whole (...), and there is no simple expression for face (and none at all for hand or foot)". Another contributor (Burenhult, 2006, p. 169) suggests that in the Mon-Khmer language Jahai there is no word for 'head'.

These are startling claims indeed, and if true, they would have important implications for the on-going debates concerning human universals and the extent of conceptual diversity among human groups.

The authors of the Introduction to the Special Issue (Enfield et al., 2006, p. 146) write:

We offer this collection as a step in reviving interest in the empirical study of the way in which human beings conceptualize and categorize their bodies as physical entities with parts. While much scholarly interest in the study of meaning has presupposed that the human body is a basic pre-linguistic source for conceptual structure (feeding

\footnotetext{
${ }^{1}$ The analyses presented in this paper owe a great deal to extensive discussions with Cliff Goddard and in most cases have been arrived at jointly. The explications in Section 8 represent our joint work.
} 
into embodiment, metaphor, semantic extension, etc.), it may be that there are fewer points of convergence across language communities in the concrete vocabulary of the body than previously imagined. (Emphasis added)

While the Special Issue indeed provides a great deal of interesting new data, it offers no firm broader conclusions, beyond that speculative "may be". In so far as it does reach for generalizations, it seeks to undermine, without adequate argumentation, those conceptual universals which had been either established or firmly hypothesized before.

Speech communities without a concept of 'body'? Without a concept of 'hands'? Without a concept of 'head'? Everything is possible, but such claims, which risk exoticising many human groups far away from Europe and other centres of Western culture, should not be made lightly. (On this point, see Keesing's brilliant 1994 essay "Radical cultural difference: Anthropology's myth?').

To claim that some far-away language has no word for 'hands' just because it uses the same word for 'hands' and (roughly) 'arms', is like saying that Russian has no word for 'hands' because the Russian word ruki can mean either 'hands' or (roughly) 'arms'; or that English has no word for 'head' (as a body part) because the English word head can also be used in some other senses.

As the authors of the Introduction acknowledge themselves (p. 138), "a critical analytic distinction which requires case-by-case investigation is the status of a linguistic expression as either ambiguous (having numerous distinct meanings) or semantically general (vague)". But the contributors to the Special Issue have no semantic methodology which would allow them to make this critical analytic distinction, and as a result they exoticise languages where terms for, for example, 'body' or 'hands' are truly polysemous.

The "Elicitation guide on parts of the body" (Enfield, 2006a) focuses heavily on the "extensional range of body part terms". It encourages the fieldworker to "try to determine, as clearly as possible, the precise extensions of the term" (p. 153). To this end, it suggests procedures such as asking the consultant "to name the various body parts, drawing outlines (...) of the specified body parts on the illustrations" (Enfield, 2006a).

The question about the "intentional content of body part terms" (p. 154) is also raised, and the fieldworkers are encouraged to address it, but they are not given any clear and precise methodological guidelines. The issue of "ambiguity vs. generality" is mentioned, and "language-internal tests" are recommended (p. 155), but the methodological guidance offered is actually minimal. Apart from a reference to Cruse's Lexical Semantics, the extensive semantic literature on the issue of polysemy and ways of resolving it is, by and large, ignored. (Cf. e.g. Apresjan, 1991, 2000; Goddard, 1998; Langacker, 1990; Lyons, 1977; Ravin and Leacock, 2000; Weinreich, 1980; Wierzbicka, 1996.)

One cannot decide issues of polysemy "empirically", without a semantic theory, on the basis of a simple test such as conjoinability. The reasoning goes as follows: in English, one can say "the head and the body", so body has two meanings in English (1. body as a whole, 2. the trunk); but if in some other language the same word is used for the 'body' and also for 'skin' and one cannot easily produce in that language a conjoined phrase contrasting the skin with the rest of the body, then the word in question is not polysemous and the language has no lexically embodied concept of 'body'.

This is not persuasive. There can be many reasons why such attempts at conjoining two words may not work. This fact by itself does not demonstrate conclusively the absence of polysemy. Similarly, instructing native speakers of a field language to perform grisly 
mental experiments such as counting (in their minds) amputated body parts hypothetically collected in one place (see, e.g., Terrill, 2006) cannot decide conclusively whether words used in such experiments are or are not polysemous. Most obviously, one cannot establish a word's polysemy by the sort of colouring task which plays such an important role in the research reported in the Special Issue (e.g., in investigating by such methods whether or not a word like the Russian ruka 'hand/arm' is polysemous, the consultants might well colour the whole arm).

Ultimately, the only way to establish whether a word is polysemous or not is to show what the hypothetical "general" or "vague" meaning might be. This, however, requires a method for defining (articulating) meanings and testing them against a given word's range of use. No such definitions are proposed in the Special Issue - perhaps a natural result of the fact that while the contributors were urged to distinguish "ambiguity from generality", they were apparently not encouraged to try to figure out what the meaning of an indigenous term might be: the only conclusive test for establishing the "generality" - delivering the goods, producing a plausible "general" (unitary) definition - was not even mentioned in the guidelines.

Emphasizing the importance of the human body for semantic typology, the authors of the Introduction note that "our bodies are central to daily existence" (p. 138). They do not, however, go further to acknowledge that they are central to our existence in general; and that they provide for us a reference point in interpreting the world and orienting ourselves in it (see Section 11). Having called the body, somewhat strangely, "an environmental universal", the authors make the important point that "the human body is a rich resource for exploring fundamental issues about the nature of categorization" (p. 138). They then raise the fundamental questions: "How similar, or different, are cognitive categories? How do people of radically different cultures categorize and conceptualize the very same world?",

But precisely because these questions are so fundamental, it is important to get the answers right, and to acknowledge adequately both the conceptual diversity of speakers of different languages and what Franz Boas called the "psychic unity of mankind" (Boas, 1938). In my judgment, the Special Issue does not get this balance right.

A quarter of a century ago, Hallpike (1979) in his Foundations of Primitive Thought claimed that various "primitive" tribes in Papua New Guinea fail to distinguish the concepts of 'knowing' and 'thinking' from the concept of 'hearing', because they use the same word for 'know' and for 'hear', or for 'think' and for 'hear'. Following in his footsteps, Bain (1992, p. 86) made similar claims about the Australian language Pitjantjatjara: "There is no way to differentiate the concepts of thinking, listening and hearing in Pitjantjatjara. The same verb kulini does duty for all...”. (For discussion, see Wierzbicka, 1994, 1996; Goddard, 1998).

The claims made in the Special Issue about the failure to differentiate between 'hands' and 'arms', or between 'body' and 'person', in some Papuan and Australian languages (because the same word "does duty for all") bring to mind the Hallpikean tradition in cognitive anthropology. Of course the contributors to the Special Issue do not write, and no doubt do not think, in terms of "primitive thought", but at some points their semantic methodology is, nonetheless, reminiscent of Hallpike's.

Like Hallpike, the contributions to the Special Issue attempt to practice "cognitive anthropology" in a theoretical vacuum and have no methodology for distinguishing genuine and spurious polysemy, and like Hallpike, they apply a double standard with respect 
to "exotic" languages and European ones. A decade ago, in my critique of Hallpike, I wrote (Wierzbicka, 1996, p. 198):

It is true that many non-Western societies use the same word for 'think' and 'hear' or for 'know' and 'hear'. But what exactly does that prove? In English one can use the word see to mean 'understand' ("I see what you mean ..."), but this does not prove that the speakers of English do not distinguish the concept of 'understanding' and the concept of 'seeing'. (Similarly, in French entendre can mean either 'hear' or 'understand'; but this does not prove that the speakers of French do not distinguish the concepts of 'hearing' and 'understanding').

Exactly the same applies to the words discussed in the Special Issue. It goes without saying that it is important not to invent polysemies unnecessarily, but it is also important not to invent fundamental conceptual differences between human groups unnecessarily. Systematic semantic analysis in the NSM framework (see Section 2) allows us to reconcile these two desiderata and leads to the conclusion that while many concepts are languageand culture-specific, the concept of BODY is universal, just as the concepts of KNOW and THINK are universal. ${ }^{2}$ It also leads to the conclusion that while there are considerable differences in the conceptualization and categorization of body parts across languages and cultures, the basic model of the human being is something that we all share.

Arguably, the solidarity of the "human race" depends, among other things, on the recognition that despite all human diversity, we share more than "the physical universal" of the body: we also share some fundamentally human ways of thinking. It is important to find out just what our shared conceptual currency is.

\section{The natural semantic metalanguage (NSM): semantic primes and semantic molecules}

To compare meanings cross-linguistically, one needs a semantic theory and methodology. The Natural Semantic Metalanguage (NSM) framework makes such comparisons possible. The hallmark of the NSM system is that meanings are represented in a tightly constrained, yet expressively flexible, "mini-language" of empirically established universal semantic primes along with their inherent universal grammar.

Semantic primes are simple indefinable meanings which "surface" as identifiable wordmeanings in all languages. These include meanings such as SOMEONE/PERSON, SOMETHING/ THING, PEOPLE, KIND, PART, WHERE/PLACE, WHEN/TIME, DO, HAPPEN, MOVE, TOUCH, THINK, WANT, KNOW, SAY, GOOD, BAD, BEFORE, AFTER, BECAUSE, IF, NOT, LIKE, and others.

The total number of primes is in the mid-sixties. They are displayed in Table 1, which uses exponents from English and Table 2, which uses exponents from Polish. Comprehensive descriptions of the natural semantic metalanguages of English, Malay, Mandarin Chinese, Lao, Mangaapa Mbula (Papua New Guinea), Polish and Spanish are available in Goddard and Wierzbicka (2002). The studies in Peeters, in press provide overviews of NSM from the perspective of French, Italian, Portuguese and Spanish. Other cross-linguistic studies of the realization of semantic primes and their grammar include Yoon (2004, 2006) for Korean, Goddard and Karlsson (2004) for Swedish, Junker (2003) and Junker and Blacksmith (2006) for Cree, and the studies in Goddard and Wierzbicka (1994a,b).

\footnotetext{
${ }^{2}$ It is an NSM convention to use small caps for empirically established universal semantic primes.
} 
Table 1

Semantic primes - English exponents

\begin{tabular}{ll}
\hline Substantives & I, YOU, SOMEONE/PERSON, SOMETHING/THING, PEOPLE, BODY \\
Relational substantives & KIND, PART \\
Determiners & THIS, THE SAME, OTHER/ELSE \\
Quantifiers & ONE, TWO, MUCH/MANY, SOME, ALL \\
Evaluators & GOOD, BAD \\
Descriptors & BIG, SMALL \\
Mental predicates & THINK, KNOW, WANT, FEEL, SEE, HEAR \\
Speech & SAY, WORDS, TRUE \\
Actions, events, movement, contact & DO, HAPPEN, MOVE, TOUCH \\
Location, existence, possession, specification & BE (SOMEWHERE), THERE IS/EXIST, HAVE, BE \\
Life and death & LIVE, DIE \\
Time & WHEN/TIME, NOW, BEFORE, AFTER, A LONG TIME, \\
& A SHORT TIME, FOR SOME TIME, MOMENT \\
Space & WHERE/PLACE, HERE, ABOVE, BELOW, FAR, NEAR, SIDE, INSIDE \\
Logical concepts & NOT, MAYBE, CAN, BECAUSE, IF \\
Augmentor, intensifier & VERY, MORE \\
Similarity & LIKE \\
\hline
\end{tabular}

Table 2

Semantic primes - Polish exponents

\begin{tabular}{ll}
\hline Substantives & JA, TY, KTOŚ, COŚ, LUDZIE, CIALO \\
Relational substantives & RODZAJ, CZEŚĆ \\
Determiners & TEN, TEN SAM, INNY \\
Quantifiers & JEDEN, DWA, DUŻO, NIEKTÓRZY/NIEKTÓRE, WSZYSCY/WSZYSTKO \\
Evaluators & DOBRY, ZZY \\
Descriptors & DUŻY, MAŁY \\
Mental predicates & MYŚLEĆ, WIEDZIEĆ/ZNAĆ, CHCIEĆ, CZUĆ, WIDZIEĆ, SŁYSZEĆ \\
Speech & POWIEDZIEĆ/MÓWIĆ, SŁOWO, PRAWDA \\
Actions, events, movement, contact & ROBIĆ, DZIAĆ SIÉ/STAĆ SIĘ, RUSZAĆ SIÉ, DOTYKAĆ \\
Location, existence, possession, specification & BYĆ (GDZIEŚ), BYĆ (ISTNIEĆ), MIEĆ, BYĆ (CZYMŚ/KIMŚ) \\
Life and death & ŻYĆ, UMRZEĆ \\
Time & KIEDY/CZAS, TERAZ, PRZED, PO, DŁUGO, KRÓTKO, PRZEZ PEWIEN CZAS, \\
& CHWILA (W JEDNEJ CHWILI) \\
Space & GDZIE/MIEJSCE, TUTAJ, NAD, POD, WEWNĄTRZ/W, \\
& Z (KTÓREJ) STRONY, BLISKO, DALEKO \\
Logical concepts & BO /Z POWODU, JEŻELI, NIE, BYĆ MOŻE, MÓC \\
Augmentor, intensifier & BARDZO, WIECEJ \\
Similarity & TAK (JAK)
\end{tabular}

Notes:

- Primes exist as the meanings of lexical units (not at the level of lexemes).

- Exponents of primes may be words, bound morphemes, or phrasemes.

- They can be formally complex.

- They can have different morphosyntactic properties, including word-class, in different languages.

- They can have combinatorial variants (allolexes).

- Each prime has well-specified syntactic (combinatorial) properties.

Semantic primes provide a principled "vocabulary" for semantic-conceptual representation: clear, accessible, minimal, non-circular, non-ethnocentric. Because the vocabulary and syntax of NSM are recruited from ordinary language, it can achieve much greater 
clarity and accessibility than is possible with more technical and more obscure modes of representation. Because the metalanguage is minimal in size, one can achieve maximum resolution of semantic detail and ward off any possibility of circularity. It is or aspires to be a formal semantic metalanguage based on natural language.

It is not the case, however, that all lexical meanings can be resolved directly or immediately to the level of semantic primes. Some are best explicated in stages, using intermediate-level "semantic molecules", which themselves can be resolved into configurations of semantic primes; cf. Wierzbicka (1996, p. 221; in press-a,b); Goddard (1998, pp. 254-255; 2006; in press-a). For example, the optimal explications for physical activity verbs such as eat, hit, and run rely on body-part meanings such as 'mouth', 'hands', and 'legs', in combination with semantic primes. Semantic molecules enable a kind of "chunking" in the semantic structure of complex concepts. Where semantic molecules are used in the present study, as they frequently are, they are marked as such by the notation [M].

In the NSM system, meanings are represented by means of extended explanatory paraphrases, known as "explications". NSM semantic explications have to meet three conditions: (i) well formedness, i.e., they have to be framed exclusively within the NSM metalanguage, as just described; (ii) coherence, i.e., they have to make sense as a whole; and (iii) substitutability, i.e., they have to make intuitive sense when substituted into their contexts of use, generate the appropriate entailments and implications, and so on.

Three further general points perhaps warrant emphasis. First, the NSM system aims to be exhaustive, i.e., capable of adequately paraphrasing the entirety of the vocabulary of any language. Second, the explicatory phrases offered in this framework are not tied to a single language (e.g., English), but can be formulated, in principle, in any natural language (see, e.g., Goddard and Wierzbicka (Eds.), 2002, vol. I, pp. 165-167, 235-237, 313-315; vol. II, pp. 58-60, 138-140, 247-249). Third, a large body - literally hundreds - of descriptive-analytical studies have been conducted in the framework, dealing with lexical, grammatical and illocutionary semantics across many domains and across many languages. ${ }^{3}$ Crucially, an NSM explication is intended as a conceptual representation as well as a semantic one: what is of interest to NSM is not just formal elegance or ingenuity, but the psychological reality.

\section{The universality of body}

According to the research done within the NSM framework, 'body' is a universal human concept (cf. Wierzbicka, 1999; Goddard, 2001; Goddard and Wierzbicka, 2002). The concept of 'mind', widely used and often taken for granted in Anglophone science and philosophy, is highly language-specific, and so are its nearest counterparts in other languages, such as 'duša' in Russian, 'kokoro' in Japanese, 'maum' in Korean, 'hati' in Malay, and so on (Wierzbicka, 2005; Yoon, 2004; Goddard, 2001, in press-b). But 'body' as a conceptual universal has so far passed all rigorous semantic testing with flying colours.

In his broad-based cross-linguistic study of lexico-semantic universals and near-universals, Goddard (2001, p. 15) noted: "Early surveys of body-part nomenclature (Brown,

\footnotetext{
${ }^{3}$ For an extensive bibliography, see the NSM Homepage: une.edu.au/arts/LCL/disciplines/linguistics/ nsmpage.htm.
} 
1976; Andersen, 1978) claimed that the meaning 'body' is indeed universally lexicalized, but such claims have also been disputed, (...) many of the counter-claims are to be found in the anthropological literature, where either insufficient data is given to decide whether or not polysemy is involved, or the data is at best equivocal'. In particular, Goddard rejected the claim of the anthropologist Lewis (1974), cited in Wilkins (1996a), that in the Papuan language Gnau "there is no single word corresponding to English 'body"'. Seeking to establish 'body', contra Wilkins, as a viable semantic universal Goddard wrote:

Wilkins (1996a) charts shifts and overlaps between the meanings 'body' and 'person' (cf. English somebody), and 'body' and 'skin' in various languages, but it seems to be generally necessary, for independent reasons, to recognise polysemy in such cases. This can be illustrated from a language that Wilkins has documented in detail, namely, Arrernte (Wilkins, 1996b). The Arrernte word tyerrtye can mean, inter alia, either 'people/person' or 'body'. The existence of a separate meaning 'body' is clear in sentences like the following: (a) Ayenge welheme tyerrtye urinpe-arle-irrerlenge 'I feel my body getting hot (i.e. I'm getting a fever)', (b) Tyerrtye ikwerenhenge, intel-tnye ikwerenge anteme kemirreke thipe kngerrepenhe anteme 'From his body, from where he lay dead, there then arose a large bird'. As it happens, Arrernte has also a monosemous word for 'body', namely, arlke (Henderson and Dobson, 1994), so the existence of a lexical unit with this meaning does not hinge on the analysis of tyerrtye. In nearby Yankunytjatjara, the situation is similar. The word for 'people/person' anangu can also mean 'body', but there is also another word puntu for 'body'. (Goddard, 2001, pp. 15-16)

In the anthropological literature that Goddard refers to, the focus was on "labelling" and "nomenclature" (cf., e.g., Brown, 1976). The main question was: which body parts are "labelled". In fact, Brown (1976, p. 421) insisted explicitly that he was concerned with "naming behaviour" and not with "semantics". In NSM works on ethnoanatomy, beginning with the Introduction to my Semantic Primitives (Wierzbicka, 1972) and the chapter on "Parts of the body" in my Lingua Mentalis (Wierzbicka, 1980), the question about "nomenclature" and "naming behaviour" was replaced by a question about conceptualization, and the question about "labels", by a question about word-meanings, or concepts. When Goddard (2001) sought to establish BODY as a linguistic universal, he clarified the issue previously clouded by the constant references to "nomenclature", pointing out that what mattered was not the presence of a unique label but the presence of an identifiable word-meaning - a lexically embedded concept; and that, consequently, ethnoanatomy (and cognitive anthropology in general) needed a semantic methodology.

Unaccountably, in their Introduction to the Special Issue, Enfield and colleagues ignore Goddard's arguments about the polysemy of 'body/person' words like the Arrernte tyerrtye, even though they do refer to his paper. I will quote the relevant passage from that Introduction, too, in full:

Many have claimed that all languages have a term meaning 'body' (Brown, 1976; Andersen, 1978; Wierzbicka, 1996; Goddard, 2001), but this is not uncontroversial. Evans and Wilkins (2001) and Wilkins (1996a), for example, state that terms denoting the body are diachronically unstable, and that these terms are often polysemous, being used to refer to skin, trunk, and person, as well as to body. Wilkins (1996) argues that a term for person or human being is a better superordinate term or 
unique beginner, as it does appear to be universally named and is less likely to be polysemous. Contributors to this special issue have established the appropriate unique beginner for their languages based on internal linguistic evidence. So, while Lao, Punjabi and Yélî Dyne have 'body' as a unique beginner, Kuuk Thaayorre, Lavukaleve, Tidore and Savosavo have 'person'. (Enfield et al., 2006, p. 143)

But to begin with, the argument of diachronic "instability" is irrelevant to the issue of the universality of the concept 'body' as was pointed out by Goddard (2001, p. 15), in a note also ignored by Enfield et al.:

This may be a good place to observe that semantic simplicity and "stability" of formal realisation across time are not necessarily correlated, particularly in the case of semantic primes such as 'body', which tend to be expressed by polysemous lexemes. Not only can there be frequent and recurrent semantic shifts (cf. Wilkins, 1996a), it is known that some languages have borrowed terms for semantic primes, presumably replacing earlier indigenous words. In Malay, for example, the lexemes for 'feel' and 'think' (rasa and fikir) have been borrowed from Sanskrit and Arabic, respectively.

The assumption that the degree of diachronic stability is a good clue to synchronic analysis was also dealt with by Goddard in the following comment:

The independence of form-meaning stability and semantic simplicity is nicely illustrated by studies of the cognation rates (and by implication, retention rates) for meanings from Swedish's Basic Vocabulary List. Dyen et al. (1967) found that the five most stable items among Austronesian languages were: 'five', 'two', 'eye', 'we', and 'louse'. Pawley (1997) found the three most stable items in Trans New Guinea languages were: 'eat', 'louse', and 'I'. The only term which ranks in the top five in both families is 'louse', which (though it may perhaps be an approximate lexical universal) obviously has no claim to semantic simplicity. (Goddard, 2001, p. 15.)

The claim that the term for person or human being is a "better superordinate term or unique beginner as it (...) is less likely to be polysemous" is baffling. As noted earlier, the words for KNOW and THINK are likely to be polysemous in many languages of the world, including Papua New Guinea and Australia, but this does not undermine their status as conceptual universals (cf. Wierzbicka, 1996; Goddard, 1998; Goddard and Wierzbicka, 2002). Furthermore, the contributors to the Special Issue are happy to accept that in English, body is polysemous (1. the body as a whole, 2. the "trunk"), and also that 'nose' or 'head' is (in English) "a part of the body", not "a part of a person". Why then should not the (alleged) fact that 'person' is less likely to be polysemous than 'body' make it a 'better unique beginner" in other languages?

Surely, what matters is not what is "better" but what is true. The simplest and safest hypothesis is that people generally think of a person's head, or nose, as part of their body, and if nothing forces us to abandon this minimal hypothesis, the polysemy or monosemy of the term for body is as irrelevant as this term's diachronic stability or instability.

The claim made in the Introduction to the Special Issue that eyes and ears, or arms and legs are conceptualized in some languages as "parts of the body" whereas in other, often neighboring and closely related languages, they are conceptualized very differently, 
namely, as "parts of a person" (with no concept of 'body' being available at all) is a good illustration of how cross-linguistic differences in the human conceptualization of the world can be exaggerated beyond anything warranted by the available evidence.

In their Introduction, Enfield et al. (p. 145) assert: "Several languages do not have a general term meaning 'body'. In Tidore and Kuuk Thaayorre the highest level in the partonomy would be a word for "person"'. When one checks the papers on Tidore and Kuuk Thaayoore, however, one may well conclude that this assertion is unfounded: the authors of both these papers provide in fact some evidence that these languages do have a general term meaning 'body'.

Of Tidore, van Staden (2006, p. 332) says the following: "Loan words, although very common in almost every domain of the language, are surprisingly sparse in relation to the body. The only loan word that comes up frequently in relation to the human body is badan 'body', for which Tidore does not have a term'.

Clearly, what van Staden means is that the only word used in Tidore for 'body' is a loan word. To say that Tidore "does not have a word for 'body"' is like saying that Malay has no words for 'feel' and 'think' because (as noted in Goddard, 2001) the speakers use for these concepts the words rasa (for 'feel'), from Sanskrit, and fakir (for 'think'), from Arabic. Especially in the case of basic concepts like 'body', 'think', 'feel' or 'want', a new word may well be borrowed in order to disambiguate an earlier term which was polysemous. For example, as discussed by Hale (1994, p. 269), in some Misumalpan languages of Central America the English word for 'want' has been borrowed to replace a polysemous word meaning either 'want' or 'seek'.

As for Kuuk Thaayore, Alice Gaby's paper provides in fact more evidence for the presence of a word for 'body' than for its absence. As she reports, the word pam-minj, literally 'true man', "may be used to refer to the specifically physical presence of a human (including that purely physical human entity, the corpse)". (Gaby, 2006, p. 206). The word pamminj may or may not be polysemous, but if it can refer to a corpse, then it seems likely that one of its meanings is 'body'.

While Gaby comments that "pam-minj also includes in its scope many non-corporeal components of a living person (e.g., their tracks, voice, shadow, etc.)" all she seems to mean by this is that "these non-corporeal human parts appear in morphosyntactic constructions reserved for parts of the body" (Gaby, 2006, p. 206). But such use of "inalienable possession" constructions with reference not only to the body but also to a person's shadow, footprints, etc. is known to be widespread in the world's languages (cf., e.g., Evans, 1996, and several other papers in Chappell and McGregor (2002)). There are even certain parallels in European languages. For example, as discussed in my 1979 article "Ethnosyntax and the philosophy of grammar", in Italian one can extend a construction normally reserved for body parts to items of clothing (worn on the body) and say:

Le vedeva (guardava) le mutandine.

'To her he saw (looked at) the underpants.'

Le vedeva (guardava) una macchia sul vestito.

'To her he saw (looked at) a spot on the dress.'

implying that the underpants and the dress in question were seen on the person's body, not elsewhere (Wierzbicka, 1988, pp. 189-190). Similarly, in Polish one can say, literally, "he 
took off hat" (meaning "from his [own] head"), as one can say, literally, "he opened eyes" (meaning "his [own] eyes") (Wierzbicka, 1979, 1988), i.e., treating an item of clothing currently worn on the body as comparable to a part of the body.

Such language-specific extensions of constructions principally reserved for body parts do not show that either Italian or Polish does not have a word for 'body'. Similarly, nothing in Gaby's account establishes that Kuuk Thaayore has no word for 'body' either. Clearly, the matter requires further investigation, but equally clearly, there is no sufficient basis at this stage for asserting, as Enfield et al. (2006, p. 145) do, that in Kuuk Thaayore there is no word for 'body'.

The absence of any rigorous semantic analysis to back up the claim that the language described "has no word for 'body", (an no word for 'part') is particularly striking in the contribution on the Amazonian language Tiriyó. To quote (Meira, 2006, p. 277):

The basic word in the hierarchy, punu, means 'flesh, meat' as well as (and in fact more often than) 'body'. It is more of a mass, 'stuff' noun than a cover term for a large structure. As a secondary element, it occurs in several derived body part terms that describe 'fleshy' places (e.g. nma-punu 'buttocks', ewa-punu 'calf of leg'. Although all speakers agreed that it could be used as the main word in the hierarchy (i.e. that it 'has' other external body parts, or that they could be 'located on' it) there seem to always be 'fleshy' overtones. In text materials, flesh/meat meanings like 'I eat tapir meant' are the most frequent. This seems to be a case of semantic generality. (A similar situation seems to obtain with English body, both 'body as a whole' and 'trunk, part to which the limbs are attached'.)

As this quote illustrates, the author's treatment of this point is superficial and impressionistic. It is not enough simply to say that "this seems to be a case of semantic generality", with the only supporting observations being that the 'fleshy' usage is much more common and that other uses "seem" to have 'fleshy overtones'. The relative frequency of putative meanings is irrelevant to the issue of discreteness or non-discreteness of meanings.

To decide whether it is semantic generality or polysemy, it is necessary to undertake a thorough investigation, making reference to standard lexicographic techniques, e.g. checking whether contrastive readings are possible, checking whether any derivational processes select one putative meaning over another, whether any morphosyntactic properties attach to one meaning or the other, whether they have different antonyms (e.g. 'body' - 'spirit', 'flesh' - 'bone'), and so on.

One ought to check how/whether expressions such as the following could be expressed in Tiriyó: 'the body of a man is not like the body of a woman'. Also relevant would be whether hard body-parts such as bones and teeth are regarded as "parts of the punu"; if so, one could hardly maintain the notion that punu has "fleshy overtones". (Incidentally, the comparison with English 'body' is misplaced: contrary to the author's assertion unsupported by reference to any literature or evidence it is quite clear that the English lexeme body has two meanings - 'body' and 'trunk'. In fact, as already noted, this point is recognized elsewhere in the Special Issue, e.g. in Enfield, 2006b, p. 184). It is of course theoretically possible that one day a language will be found without a word for 'body' (whether polysemous or not). Until such day, however, we can safely assume that regardless of what their native language happens to be, people everywhere in the world think of people as having a 'body', and also, that they think of, for example, a person's head as a part of this person's body, and that the elaborated universal model of a human being put forward in 
Wierzbicka (2005) and reproduced below stands (at least as far as the claim of 'embodiment' is concerned). ${ }^{4}$

\section{The universality of PART}

The hypothesis that the human body is conceptualized, universally, in terms of 'parts', depends of course on the assumption that the concept of 'part' itself is universal. In NSM work, this prior assumption was adopted, as a working hypothesis, from the outset. Thus, when the first list of universal concepts, which included only 14 elements, was postulated in my Semantic Primitives (Wierzbicka, 1972), PART was one of that first batch. The hypothesis was re-affirmed a decade later in my Lingua Mentalis (Wierzbicka, 1980), which included some 80 tentative explications of body-part words, ${ }^{5}$ and again, in Semantics: Primes and universals (Wierzbicka, 1996).

By that time (the mid-nineties), the universality of 'part' had become a controversial issue, partly because the earlier NSM claims on the subject were often misunderstood. In response to various dissenting comments, I wrote (1996, p. 60; see also pp. 142-143):

PART is a controversial primitive, partly (no pun intended) because many languages don't have a word with a range of similar use to that of the English noun part, and partly because some languages don't seem to have a word for part at all.

\footnotetext{
${ }^{4}$ A human being - the universal model

"Existential" aspect

someone

this someone has a body

this someone can live

this someone can die

this someone can do many things

many things can happen to this someone

"Psychological" aspect

this someone can know things

this someone can want things

this someone can think about things

this someone can feel some things (feelings)

this someone can say things

this someone can see things

this someone can hear things

"Social" aspect

this someone can do things with other people

this someone can live with other people

this someone can say things to other people

"Moral" aspect

this someone can do good things

this someone can do bad things.

5 Needless to say, by today's NSM standards, those 80 or so explications, constructed over a quarter of a century ago, are obsolete. Nonetheless the main ideas on which they were based are still relevant today: the use of the primes BODY, PART, ABOVE, BELOW, ON (ONE) SIDE, PLACE, the use of "topographic" as well as partonymic relations, the assumption of the basic duality of 'eyes', 'ears', 'arms' and 'legs'.
} 
In proposing PART as a universal semantic primitive, therefore, it is important, first of all, to clarify which uses of the English part are meant to illustrate the postulated primitive; and second, to examine how the meaning in question is expressed in a language which does not seem to have a word corresponding to the English part at all.

Trying to clarify the issue, I noted, inter alia, that cultures differ in the amount of interest they show in the concept of 'part':

As argued in Goddard, 1989, modern Western culture places a great emphasis on viewing various aspects of reality in terms of complexes analysable into 'parts', whereas, for example, Australian Aboriginal culture does not. But cultural differences of this kind should not obscure the fact that the concept of PART can also be expressed in those languages whose speakers are less inclined to talk about "parts" in the abstract (in contrasts to heads, feet, handles, and other specific kinds of "parts") than are speakers of technologically complex modern societies. (Wierzbicka, 1996, p. 61)

The issue of the universality of PART was discussed again, at some length, in Goddard's (2002a) paper "The search for the shared semantic core of all languages" in our edited book Meaning and Universal Grammar, where he wrote (p. 30):

Linguists seem to agree that the part-whole relationship is fundamental to the vocabulary structure of all languages, but there are certainly languages which do not have a unique lexical form for the postulated semantic prime PART (OF). This does not necessarily mean, however, that these languages lack a lexical unit with the meaning PART. In three unrelated languages in which such an apparent gap has been investigated (Acehnese, Mangaaba-Mbula, Yankunytjatjara) it appears that PART exists as the meaning of a lexical unit of the same lexeme which can also mean someTHING, THING, Or WHAT.

In these languages the meaning PART is expressed when the relevant lexical form is used in a grammatical construction associated with possession. (It is as if instead of saying, for example, 'the nose is a part of the face' one says "the nose is a thing of the face".)

These carefully phrased statements were illustrated by Goddard with the following examples:

Yankunytjatjara:

Puntu kutju, palu kutjupa-kutjupa tjuta-tjara.

body one but something-RDP many-having

'(It is) one body, but with many parts.'

Acehnese:

Bak geuritan angèn na lè peue.

at vehicle wind there is many what/something

'A bicycle (lit. wind-vehicle) has many parts.' 
Mangaaba-Mbula:

Iti tomtom na koroN-Na-nda boozo kumbu-ndu, nama-nda.

we person GIV thing-NMZ-our many leg-our head-our

'We people, our parts are many: our legs, our heads, ...'

The contributors to the Special Issue who say that in their field language "there is no word for "part"" appear to be unfamiliar with the clarifications offered in the works quoted above. Thus, Gaby (2006, p. 207) reports "the apparent lack of an expression corresponding to part of" in Kuuk Thaayorre, adding that "Kuuk Thaayorre is by no means the only language to lack such expression"; and she comments that "this runs counter to Wierzbicka's (1994, p. 489) proposition that the relational concept part of is a (universally lexicalized) semantic primitive". Unfortunately, she does not refer to the subsequent NSM discussions of the issue, and neither does the Introduction.

The misunderstandings concerning PART as a hypothetical universal concept could have been avoided had the contributors to the Special Issue been advised to test with consultants some canonical NSM sentences devised to test this hypothesis cross-linguistically (such as, for example, "our bodies have many parts", or the sentences from Goddard's (2002a,b) study quoted above. $)^{6}$

To see the results of such tests, the interested reader can consult studies like the following ones, concerning a wide range of typologically diverse languages: Ewe (Ameka, 1994), Mbula (Bugenhagen, 1994, 2002), Mandarin (Chappell, 1994, 2002), Thai (Diller, 1994), Achenese (Durie et al., 1994), Kayardild (Evans, 1994), Yankunytjatjara (Goddard, 1994), Misumalpan languages (Hale, 1994), Arrernte (Harkins and Wilkins, 1994), Longgu (Hill, 1994), Japanese (Onishi, 1994), Malay (Goddard, 2002b), Spanish (Travis, 2002), Polish (Wierzbicka, 2002), Lao (Enfield, 2002), Korean (Yoon, 2006), Swedish (Goddard and Karlsson, 2004), and Cree (Junker, 2003; Junker and Blacksmith, 2006).

\section{5. 'Hands' as a universal lexico-semantic molecule}

As far as parts of the body are concerned, the NSM theory has so far proposed (in this case, more recently and more tentatively) one conceptual universal: "hands". Unlike BODY, which has been proposed as a semantic prime, the concept of 'hands' is clearly decomposable into simpler concepts: it involves, at the very least, the primes BODY, PART and TWO. Thus, the NSM explication of the English word "hands" (see Wierzbicka, 2003, 2004, in press-a) starts with the line "two parts of the body". According to this explication, the concept of 'hand' (in the singular) is derived from that of 'hands' (in the plural); and the same holds for several other paired and symmetrical parts of the human body:

\footnotetext{
${ }^{6}$ This particular NSM finding - that in many languages the word for 'thing' or 'something' can function as an exponent of PART - is in fact utilized (though not sourced) in the Special Issue's "Elicitation Guide" (p. 156), where the contributors are told that, e.g., a meaning expressed in English as the arms are parts of the body may be expressed in some languages by an idiomatic construction along the following lines: "The arm is the thing of the person" (p. 156).

7 The explication of hands presented here is a shortened version of that proposed in earlier work (see Wierzbicka, 2003, in press-a). The additional components of the earlier versions represent, I now think, aspects of universal folk-knowledge about the human hands rather than a part of the concept as such.
} 
'eyes', 'ears', 'legs', and some others (but not, for example, for 'thighs', 'knees' or 'ankles'; see below).

As argued in a substantial body of NSM work, the concept of 'hands' underlies vast numbers of other concepts: obviously nouns like fingers, gloves, and handle and verbs like slap, stroke and tear, but also verbs of physical activity involving an instrument, such as cut and chop, adjectives of physical properties like hard, soft and sharp, shape adjectives like long, round, and flat, and hundreds of 'concrete' nouns (Goddard, in press-a, in press-b; Wierzbicka, in press-a). In particular, in my 1985 book Lexicography and Conceptual Analysis I proposed several dozens of explications for various artefacts as well as "natural kinds", pointing out the crucial role of 'hands' in the conceptual structure of these concepts. For example, it is essential for the concept of a 'cup' (as in a teacup) that a person can hold it in one hand.

As I put it in my 2003 paper for the International Cognitive Science Conference, human hands mediate to a very large extent, between the world and the human mind. The fact that 'hands' are fundamental in human thinking is reflected in the relative semantic simplicity of this concept: it appears that of all the body-part concepts this is the only one which can be explicated directly in universal semantic primes, and without any reference, direct or indirect, to any other parts of the body. 'Arms', 'legs' and arguably, 'head' require in their explications a reference to shape, and 'eyes', 'ears', 'nose' and 'mouth' appear to require a reference to 'head', but an explication of 'hands' can be couched exclusively in primes, without any use of shape concepts which are inherently semantically complex. (One of the components given below, (e), can be harder to understand and to intuitively accept than others. The rationale for this component will be explained later (see p. 26)).

\section{hands}

a. two parts of someone's body

b. they are on two sides of the body

c. these two parts of someone's body can move as this someone wants

d. these two parts of someone's body have many parts

e. if this someone wants it, all the parts on one side of one of these two parts can touch all the parts on one side of the other at the same time

f. because people's bodies have these two parts, people can do many things with many things as they want

g. because people's bodies have these two parts, people can touch many things as they want

Enfield (2006b, p. 198) writes: "It is possible that most if not all relations between body parts are expressible in terms of location", and he applies this suggestion, inter alia, to the 'hand' / 'arm' relation: the 'hand' is not, according to him, conceptualized as a part of the arm (or as attached to the arm), but as located at the end of the arm: "the hand is at the end of the arm".

My own hypothesis is different: "hands" are conceptualized neither as "parts of the arm", nor as "located at the end of the arm" (not to mention any "attachment" to the arm), but as "two parts of the body". 'Hands' are far too important in human cognition to be conceived of as two flaps at the end of people's arms: they are universally conceived of as two parts of the body, just as the 'head' is universally conceived of as 'a part of the body' - they are not mediated via the concept of 'arm'. 
But the claim that the concept of 'hands' plays a key role in the human conceptualization of the world would be considerably weakened if it emerged that some human groups (in the Solomon Islands, Papua New Guinea or elsewhere) did not have such a concept. Since the most reliable evidence for the presence of such a concept is the presence of a word, the question of whether all languages have a word for 'hand' is of great importance to both cognitive anthropology and cognitive science.

As discussed earlier, however, to prove the presence of a concept in a given speech community it is not necessary to show that there is a distinct (separate) word for it: if there is a word for a concept, it does not matter, or it should not matter (from the point of view of cognitive anthropology) whether this word is monosemous or polysemous.

It has been known for a long time that numerous languages of the world use the same word for the 'hand' and for the "upper limb as a whole" (cf. Brown, 1976). This does not show, however, that these languages have no word for 'hand', if there are good reasons to think that the word in question is in fact polysemous. Thus, when we ask about the conceptual universality of 'hands' we are not asking about the presence of a word used only with that meaning. Rather, we are asking if there is a distinct word-meaning, identifiable on language-internal grounds and expressible in every language.

Levinson (2006) states that in the Papuan language Yélî Dnye "the term kêe for 'arm' includes 'hand', for which there is no separate term" (p. 227). He also says that "in this language, (...) there [is] no word for hand or foot". In saying this, he slides imperceptibly from "there is no separate term for hand" to "there is no word for hand". A similar slippage can be observed in Angela Terrill's paper on another Papuan language, Lavukaleve, of which she says that "there is no term at all that will unambiguously refer to hand" (p. 316), and also, that "there is no term for hand" (p. 307).

But there is a crucial difference between there being no word for hand at all and there being no unambiguous (i.e., separate) word for hand. To say that in Yélî Dnye or in Lavukaleve "there is no word for hand" is like saying that there is no word for hand in Russian or Polish. For a native speaker of Polish like myself, this is intuitively incorrect, and, I would argue, it is also semantically unsustainable.

It indeed makes sense to say that English (or Polish) has no word for the area of the body above the hip on which young children can be easily carried (a concept for which the Australian language Thaayorre has the word nhit, Gaby, 2006, p. 212), or that English (or Polish) does not have a word for the front of the neck (a concept for which the Amazonian language Tiriyo has the word eena, Meira, 2006, p. 270). But, as mentioned before, to say that Polish has no word for hands (just because the Polish word rece can be ambiguous) is like saying that English has no word for 'body' because the word body has also another meaning, roughly, 'trunk'

Before moving on to Polish, it should be noted that Papuan languages differ in making, or not making, a lexical distinction between 'arm' and 'hand'. For example, Koromu (Priestley, p.c.) and Watam (Foley, 1997) are like Yélî Ndye in this respect (one word for 'arm' and 'hand'), whereas Yimas (Foley, 1997) does distinguish lexically between the two. How likely is it that such a lexical difference among neighbouring (if not

\footnotetext{
${ }^{8}$ To say that some languages do not have a word for hands may have a certain shock value, but there is a difference between shock value and truth value.
} 
necessarily genetically related) languages would be linked with a conceptual difference as profound as the presence vs. absence of the concept 'hands'?

Levinson (2006, Abstract) himself states that although there is no term in Yélî Dnye for 'leg', "this is a lexical not a conceptual gap, as shown by the alternate taboo vocabulary", commenting further that the presence of a word for leg in the taboo language "removes any doubt we might reasonably have had about whether Rossells [i.e. the speakers of this language] actually fail to conceive of the leg as a unitary body part" (p. 232). But could the absence of a word for 'hand' different in form from the word for 'arm' prove that in this case there is indeed a conceptual gap and that the speakers fail to conceive of 'hands' as a body part?

Should we not hypothesize, instead, that there is no such conceptual gap in the case of 'hands' either and that the word kêe (which he glosses as 'arm/hand') is polysemous, and then check if such a hypothesis would be compatible with the available linguistic data?

The NSM theory has always insisted that polysemy should not be posited unnecessarily and it has proposed an "experimentum crucis" for debunking any unfounded claims of polysemy (see, e.g., Wierzbicka, 1996; Goddard, 2000). This "crucial experiment" consists in explicating a hypothetical unitary meaning in an independently justified set of semantic primes. If such a unitary explication can be produced and if it can account for the range of a word's use, then there is no polysemy. If, on the other hand, it is not possible to produce a unitary explication consistent with the word's range of use, then positing polysemy is justified.

I will illustrate how this "crucial experiment" works with the Polish word for legs and feet, nogi (singular noga). Colloquial Polish makes no lexical distinction between 'legs' and 'feet', and while there is also the word stopy 'feet', this word is normally not used in everyday language. For example, while in the English translations of the Bible Jesus washes the Apostles' feet, in Polish translations he washes their nogi (roughly, legs). Generally, the English sentence (e.g., directed to a child): Wash your feet! would be rendered in Polish as Umyj nogi 'wash your "legs"". In a shoe shop, too, 'feet' would be normally referred to as nogi. For example, when in English one might say "my feet are too big", in Polish one would say mam za duże nogi, meaning the feet, not the whole legs.

Does this mean that the Polish word nogi has two meanings: 1. legs, 2. feet? I would argue that it does not: a reference to "flat-bottom part" is simply a very salient part of the meaning of the Polish word noga (roughly, 'legs') and so this word can be used to refer to those salient bottom parts (in English, feet). The apparent (but only apparent) polysemy of nogi can be compared with the apparent (but only apparent) polysemy of the English word eyes: when one says in English that someone has "blue eyes" one does not mean that the whole eyes are blue, but only their salient round coloured parts ('irises").

The crucial test for the monosemy of the Polish word nogi is provided by the following unitary explication of nogi:

nogi

a. two parts of someone's body

b. they are below all the other parts of the body

c. they are long [podtuzine $[\mathrm{M}]]$

d. these two parts of someone's body can move as this someone wants

e. because people's bodies have these two parts, people can move in many places as they want 
f. the bottom[M] parts of these two parts of the body are flat $[\mathrm{M}]$

g. when people are moving somewhere for some time as people move somewhere when they are moving because they want to be somewhere else when these bottom parts[M] of these two parts of the body touch the ground[M]

As we will see later, the explication of the English word legs includes only five components out of these seven (a-e). This difference between the two explications, that of nogi and that of legs, accounts for the different ranges of use of the two words.

The absence of any reference to the "flat bottom parts" in the explication of legs is linked with the presence in English of a separate word for those parts (feet). Both native speakers' intuitions and linguistic evidence suggest that the English word feet stands, conceptually, for "two parts of the body", not "two parts of the legs". For example, if someone were wounded in a thigh, this could be reported as "he was wounded in the leg", but if they were wounded in a foot, this would not normally be so reported. In Polish, however, both cases (a wound in the thigh and a wound in the foot) could be reported in the same way, as ranny $w$ noge 'wounded in the noga'.

Thus we can cogently claim that the Polish word nogi, whose range of use is wider than that of the English legs, is not polysemous and does not mean exactly the same as the English word legs. Superficially, the situation with rece 'hands/arms' in Polish is analogous to that with nogi 'legs/feet': the word rece can be used to refer to either the arms or the hands, just as nogi can refer to either the legs or the feet. In fact, however, this analogy is spurious. First, when it is necessary to refer in Polish to the feet as such one can always use the word stopy, but when one needs to refer to the hands as such one can only use the word rece. (The literary substitute for rece, namely $d$ łonie, is very literary indeed, and I do not think I have used it in my life once.) Furthermore, there is no simple circumlocution which could possibly be used to identify a person's hands as such: the Polish equivalents of "the flat bottom parts of the arms" or of "the flat end parts of the arms" (cf. Enfield's suggestion on this point mentioned earlier) would sound as ridiculous in Polish as the English version sounds in English.

When I say in Polish "chce umyć nogi" ('I want to wash [my] nogi') I normally mean (although I would probably never put it this way) that 'I want to wash the bottom parts of my nogi'. But when I say "chcę umyć ręce" I do not mean that 'I want to wash the end parts of my arms', I mean that 'I want to wash my hands'. (For further discussion of this point see Section 9.)

Levinson (2006, p. 238) says of the Papuan language of Yélî Dnye that "not only is there no word for hand or foot, but nor is there any easy way to designate those parts - that is, the arm/hand and foot/leg terms seem to be semantically general rather than polysemous".

As I see it, the fact that in Yélî Dnye there is no easy way to designate hands without ambiguity does not demonstrate that the hand/arm term is "general rather than ambiguous". Evidently, the hands are habitually designated by the term kêe, which Levinson glosses as 'arm/hand', and evidently the speakers feel no need for another designation which would always be unambiguous. The same applies in fact to the Polish word rece and the Russian word ruki: both are "ambiguous", but nonetheless this is how Poles and Russians habitually refer to the hands as such.

In their Introduction to the Special Issue, Enfield et al. (p. 141) dismiss the hypothesis that a term which covers both 'hands' and 'arms' may be polysemous with some derision. "By this logic, one might conclude that English leg is polysemous, with two meanings 
'upper leg' and 'lower leg' (a conceivable situation). But leg refers to the whole upper and lower leg together. By the principle of parsimony, polysemy analyses should be avoided".

In fact, the two hypotheses, one concerning arm/hand words and one concerning words like the English legs, are not parallel at all. In English, nothing forces us to posit an upper leg/lower leg polysemy for legs, just as in Polish nothing forces us to posit a foot/leg polysemy for nogi; the English word legs can be easily defined without any reference to 'upper leg' and 'lower leg' along the following lines:

legs

a. two parts of someone's body

b. they are below all the other parts of the body

c. they are long[M]

d. these two parts of someone's body can move as this someone wants

e. because people's bodies have these two parts, people can move in many places as they want

The word 'long' sends us to 'hands' (which is in turn defined via universal semantic primes), but nothing in this definition sends us to "upper leg" or "lower leg". Certainly, it is foolish to postulate polysemy without necessity, but neither is it wise to reject the possibility of polysemy off-hand: parsimony is an important consideration in semantic analysis, but not the only one.

In any case, the statement that an arm/hand term in a certain language is "semantically general rather than polysemous" is just an empty assertion if no unitary definition is proposed (cf. Goddard, 2001, p. 17). On the hypothesis presented here, both the English word hands and the Polish word rece (in one of its two meanings, rece r $_{1}$ ) can be explicated in universal semantic primes as shown earlier in this section. The English word arms can be explicated along the following lines (for a full explication, see Section 8):

arms

a. two parts of someone's body

b. they are on two sides of the body

c. they are long[M]

d. the top $[\mathrm{M}]$ parts of these two parts are near the top[M] of the body

Apart from the semantic molecule 'top' (see Wierzbicka, 2006a, p. 125) the only non-primitive term occurring in this explication is the semantic molecule 'long', which has been explicated, with reference to 'hands', elsewhere (Wierzbicka, in press-a) (see Section 6).

The second meaning of the Polish word rece (rece $)$ can be explicated along similar lines (though not identically; see Section 8). But what sort of meaning could be proposed as a unitary general meaning covering both 'hands' and 'arms'? The onus is on those who have suggested that there $i s$ such a unitary indigenous meaning but have so far not attempted to show what it is.

There are two claims recurring in the Special Issue which seem to me to be incompatible: one, that in a language like Yélî Dnye (or Polish) "there is no word for hand" (but apparently, there is a word for 'arm'), and another, that a language like Yélî Dnye (or Polish) has neither a word for hand nor a word for arm but has a word for some 'general' meaning which represents a cross between the English 'hand' and the English 'arm' and 
which can only be identified in English, not in Yélî Dnye (or Polish) itself. The Special Issue does not make it clear which of these two interpretations is being proposed, but as discussed, neither of them seems tenable.

\section{The role of 'hands' as a basis for shape concepts}

One last argument for the polysemy of arm/hand words in languages which make no lexical distinction between 'hands' and (roughly) 'arms' has to do with the role of shape in ethnoanatomy, across languages. Given the complexity of this issue and its dependence on the semantics of shape, this last argument for the polysemy of arm/hand words cannot be fully presented here (for further discussion, see Wierzbicka, in press-a). Nonetheless, this argument needs to be at least signalled in the present context.

The main point has already been adumbrated: most "external" body-part concepts in all languages appear to include a reference to a given body part's shape (a point recognized by Andersen, 1978). For example, in English any plausible way to explicate the meaning of the words arms and legs must include a mention of the "long" (elongated) shape of the referents, along the following lines (partial explications only, for full explications, see Section 8.2):

arms - two long parts of someone's body on two sides of the body legs - two long parts of someone's body, below all the other parts of the body

In their article "Bodies and their parts" (whose title I have borrowed in the spirit of dialogue) the psychologists Morrison and Tversky (2005, p. 696) note that "children all over the world include in their early drawings of people a small circle over a large one, with four sticks protruding, each with smaller protrusions (Goodnow, 1977; Kellogg, 1969)", concluding that "there is good reason to believe that these body parts are regarded as important". In fact, these early drawings suggest of course not only that 'head', 'arms', and 'legs' are important, but also that they are conceptualized partly in terms of shape: the 'head' is seen as something round, and 'arms' and 'legs', as 'long'.

Unlike the other components which frequently recur in explications of body-part concepts, however, 'long', 'round' and 'flat' are not lexico-semantic universals. For example, the closest counterparts of 'long' in Polish and in the Papuan language Makasai (Brotherson, in press) do not mean exactly the same as the English long. Accordingly, to fully explicate the meaning of many body-part words we need to explicate at some point the meaning of some shape words - and as the explorations undertaken within the NSM framework suggest, shape words cannot be explicated without a reference to 'hands'.

As pointed out a long time ago by philosophers with deep insights into semantics such as Leibniz and Locke, while the concept of 'colour' is based on a reference to 'seeing', the concept of 'shape' is based on a reference to 'seeing' and 'touching': to know the 'shape' of a thing is to know those things about it that people can discover both by seeing it and by touching it (on all sides) with their hands (Wierzbicka, 2003, in press-a).

Mutatis mutandis, what applies to 'shape', applies also to specific shape concepts such as 'long', 'round', and 'flat': they include references to touching things on all sides with one's hands. This means, however, that we could not explicate the concept of 'hands' via a concept of a 'two long parts of the body on two sides of the body' ('arms'), without a vicious circle. 
The remarkable thing about 'hands' is that, unlike the explications of 'arms', 'legs', 'feet', or even 'head', an explication of 'hands' does not need to refer to any shape concepts at all: the concept of 'hands' is more basic in human thought than any shape concepts, and it is shape concepts which depend on the concept of 'hands', not the other way around.

Whether we say that the 'hand' is "a part of the arm", or that the 'hand' is "located at the end of the arm" (as suggested by Enfield, 2006a,b), we will end up in a vicious circle: the concept of 'arm' depends on the concept of 'long', and 'long' (and, for that matter, 'end') depends on the concept of 'hands' (for a detailed justification of this statement see Wierzbicka, 2003, in press-a). If we accept, on the other hand, that 'hands' are 'two parts of the body, on two sides of the body" and then proceed to fill in this rudimentary definition as shown in Section 4, using universal semantic primes, no circularity will result.

The unique feature of a person's 'hands' among all the symmetrical dual parts of the body is that all the parts on one side of one of these two parts can touch all the parts on one side of the other at the same time, and in particular, all the fingers of one hand can touch all the fingers of the other hand at the same time.

In fact, the gesture of joining one's hands in this way is familiar in many cultures as a ritual gesture of either prayer or greeting, and also, as a gesture used for various practical purposes: rubbing one's hands when they are cold, flattening dough, crushing parts of plants between one's palms for medicinal or culinary purposes, and so on. (Think also of clapping one's hands, for a variety of purposes.)

Given this unique feature of the 'hands' among all "dual" body parts, neither their exact location nor their shape is necessary for their conceptual identification, and the concept of 'hands' itself can serve as a foundational molecule on which both shape concepts (such as 'long', 'round' and 'flat') and some locational concepts such as 'ends' can be built.

\section{7. 'Hands' - universal, 'arms' - not universal}

To accept that a word which "covers both hands and arms" is probably polysemous and that one of its meanings probably coincides with that of the English hands, does not mean accepting that the other meaning of such a polysemous word will necessarily coincide, exactly, with that of the English arms. I particular, I would argue that the second meaning of the Polish word rece (in the singular, ręka) differs, to some extent, from the meaning of arms. For the meaning of arms, I have proposed the following partial explication, repeated here for the reader's convenience (see also Section 8):

arms

a. two parts of someone's body

b. they are on two sides of the body

c. they are long[M]

d. the top $\mathrm{p}_{[\mathrm{m}]}$ parts of these two parts are near the top $\mathrm{p}_{[\mathrm{M}]}$ of the body

As this explication suggests, the English word arms reflects a conceptualization focussed more on the top parts of the body parts in question than on their "end parts" ("hands"). In fact, the English word arms is polysemous and it can stand either for the whole "upper limbs" (as in the phrase $a r m s_{1}$ and legs) or for their parts other than hands (as in the phrase the hands and the arms $_{2}$ ). 
The Polish word rece 2 , on the other hand, (i.e., rece in its "upper-limb" sense) focuses clearly on the hands $\left(\right.$ rece $\left._{1}\right)$, without paying much attention to the top parts, and it could never be used to refer to "arms minus hands", as the English word arms can.

Similarly, the place underneath the top of the arm which in English is called 'underarm' in Polish is referred to by means of a different noun, pacha (pod pachą 'under arm') and would never be referred to as pod ręką 'under ręka' (Instr.). In fact, the expression pod ręką 'under ręka' would normally be interpreted as 'under one's hand'.

Thus, while $r e k a_{2}$ can refer to the whole 'upper limb', this 'upper limb' is seen here from the point of view of its most salient and most important part: the hand (reka $\left.a_{1}\right)$. Accordingly, I would propose for the Polish rece 2 an explication without component (d) of 'arms' and with an additional component (e) (see Section 9):

rece $_{2}$

a. two parts of someone's body

b. they are on two sides of the body

c. they are long

d. -...-

e. the hands $[\mathrm{M}]\left[\right.$ rece $\left._{1}\right]$ are parts of these two parts of the body

The fact that in Polish, the senses rece ${ }_{1}$ and rece $_{2}$ are covered by the same term may be an iconic indication of the close semantic link between them - closer than that between the English concepts 'hands' and 'arms'.

As mentioned earlier, Polish has also another counterpart of the English arms, ramiona - a word which in colloquial usage is usually linked with a meaning closer to that of the English shoulders (see Section 8) but which in a more literary usage can also mean something comparable to arms, and which, like arms, focuses on the top parts of the "upper limbs" rather than on the hands.

An English phrase like to hold someone in one's arms could not be translated into Polish by means of the word rece ( rece $_{2}$ ), because such a translation would sound as if one was trying to hold the other person away from one's body ("at arm's length"). In this case, then, the less common word ramiona (roughly, 'arms') would be used - or, more commonly, objęcia (plural) 'embrace'.

In fact, the monumental 11-volume Dictionary of the Polish Language (SJP, 1958-1969) defines ramie (singular) in the relevant sense as follows: "part of the upper limb, from the shoulder to the elbow joint; colloquially sometimes used to mean the whole ręka $\left[r e k a_{2}\right.$, i.e. the whole limb]'. This definition is consistent with the suggestion made here that the concept of 'ramiona' emphasizes the top part of the "upper limbs". The Dictionary offers, among others, the following example:

Zaraz na rogu milicjant z opaska na ramieniu podnióst rękę, zatrzymujac maszynę.

'At the corner, a policeman with an armband on his arm [ramie] raised his hand $\left[r e k a_{1}\right]$, to stop the motorcar'.

As this example shows, although Polish does not have an "unambiguous" word for 'hand', it clearly does have the concept, and when necessary, a distinction between 'hand' and 'arm' can be made (in this case, by using ręka $\left(r e k a_{1}\right)$ for 'hand' and the literary-sounding ramie for 'arm'). 
Thus, the Polish word ramiona (plural) has three distinct meanings, one of them comparable to the meaning of the English shoulders, another comparable to that of the English arms, and yet another comparable to that of the English expression upper arms (in all three cases, comparable, but not identical). It is not possible to explicate these three meanings, and to justify their explications, in the confines of this paper. I will only note that sorting out the meanings of words like rece and ramiona, which are very familiar to native speakers and are normally taken by them for granted, is not an easy thing to do for consultants who are not well-trained semanticists, and that even for linguists this may be a demanding and difficult task. To expect that the patterns of polysemy in this area can be easily revealed by some simple "colouring task" administered to untrained native speakers is decidedly unrealistic.

\section{Explicating English body-part terms}

\subsection{The challenge of articulating indigenous meanings}

To establish the extent of both diversity and commonality in the conceptualization of the human body across languages and cultures we need to face the challenge of explicating indigenous meanings. It is astonishing that this seemingly simple point so often goes unrecognized in publications which purport to be devoted precisely to the study of indigenous meanings. Another equally simple and, astonishingly, unrecognized point is that every description of meanings is done in some metalanguage, and that this raises the question of what a suitable metalanguage for such a task would be.

Brown (1976) acknowledged that the use of English body-part terms as a metalanguage for describing other ethnoanatomical systems was problematic, and that so was his own use of a semi-artificial metalanguage, based on the English terms and slashes ("in this paper, slash-enclosed words are referred to directly as parta; hence, /lower leg and foot/ is a parton labelled in Huastec by akau", p. 402). To his credit, he recognized that such a metalanguage "is not, of course, a perfect descriptive instrument" (Brown, 1976).

The Special Issue, too, relies, essentially, on English body-part terms and slashes, although in contrast to Brown, the contributors prefer to employ one slash between two English words rather than two slashes on two sides of an English expression (e.g., "lower leg/foot" instead of /lower leg and foot/). But this is hardly a significant methodological innovation as far as the issue of the metalanguage is concerned.

Although the other contributors to the Special Issue are silent on the subject of the metalanguage, Enfield (2006b, p. 181) does touch on this point, but apparently doesn't attach to it the slightest significance; "An inventory of around 170 Lao expressions is listed, with commentary (...) based on explicit comparison to the metalanguage, English". Yet obviously, the use of English as a metalanguage (with or without slashes) gives an Anglocentric slant to a description of indigenous meanings (cf. Wierzbicka, 2006b). Presumably, from a Huastec point of view, akau has a unitary meaning, rather than being a disjunction of two meanings expressible only in English, not in Huastec itself. As mentioned earlier, however, Brown (1976) stated that his aim was to describe people's "naming behaviour" and to "avoid suggesting that the lexical identification of entities has anything to do with meaning" (p. 421). The Special Issue, on the other hand, refers continually to "meanings", "semantics" and "conceptualization" (see, e.g., Enfield et al., 2006, pp. 145-146).

The NSM approach to ethnoanatomies frees the field both from the lingering behaviourism of "naming behaviour" and from its Anglocentric bias and it replaces 
artificial, English-based disjunctions with unitary meanings expressible not only in English but also in the indigenous language itself. To show how this can be done I will propose in this section two dozens or so explications of English body-part terms formulated in NSM, that is, in empirically established universal human concepts. The reason for this choice of illustrative material is twofold.

First, it is only by exploring the English ethnoanatomy, with which the readers are intuitively familiar, that one can allow the readers to assess the plausibility of the proposed analyses for themselves, rather than relying on someone else's specialist knowledge of a language familiar only to a single expert, or a handful of experts.

Second, to de-throne English ethnoanatomy as a privileged system for representing indigenous ethnoanatomies, we need to "de-naturalize" this particular enthoanatomical system. The English ethnoanatomy, too, needs to be understood before it can be compared, on equal terms, with others; and to understand English ethnoanatomical concepts does not mean translating them into technical English, along the lines of arms means "upper limbs". Since the word limbs itself would then need to be defined, circularly, "arms and legs", a pseudo-definition of arms based on limbs throws no light whatsoever on the indigenous English meaning of the word arms.

If a child does not understand what the word limbs means, one can explain it perfectly well by means of the phrase "arms and legs", but one could not explain the meaning of arms by means of the phrase "upper limbs".

Furthermore, to define arms as, roughly speaking, "two long parts of the body on two sides of the body" is to define it in a way which could actually explain what this word means to learners of English as a second language anywhere in the word, because this definition could be translated (with some slight approximation for long) into any language. By contrast, defining arms as "upper limbs" would explain nothing, given that most languages of the world have no word for 'limb'.

One last introductory remark, before launching into the explications. As discussed in my Lingua Mentalis (Wierzbicka, 1980, pp. 86-88), names of many human body parts are also used (with a good deal of cross-linguistic variation) in reference to animals. This appears to apply, in particular, to 'head', 'eyes', 'ears', 'tongue' and 'legs'. The explications of body-part words presented here are not intended to cover such extensions. For example, the 'head' of a snake is obviously not "above all the other parts of a snake's body". Neither the semantics of such extended uses nor the cross-linguistic variation can be discussed in the confines of this paper, but two brief examples are in order. So here are the explications of head (as in the snake's head), and of legs (as in the dog's/bird's/spider's legs):

head $_{2}$ (e.g., a snake's head)

a. one part of the body of a living thing of one kind

b. this part is like one part of people's bodies

c. this part of people's bodies is the head ${ }_{1}[\mathrm{M}]$

$\operatorname{legs}_{2}$ (e.g., a dog's, or a spider's legs)

a. some parts of the body of a living thing of one kind

b. these parts are like two parts of people's bodies

c. these two parts of people's bodies are the legs ${ }_{1}[\mathrm{M}]$ 
As these two explications illustrate, the meanings of words for the body parts of animals (and other kinds of living things) are quintessentially anthropocentric: there is a systematic relationship between the terms for human and those for non-human parts of the body. In the explications below, I will not use subscripts but the first line of these explications, which refers to 'someone's body', makes it clear that they refer to one sense of the word in question.

\section{2. "Limbs"(hands, arms, legs, feet)}

\section{$[\mathbf{A}]$ hands}

a. two parts of someone's body

b. they are on two sides of the body

c. these two parts of someone's body can move as this someone wants

d. these two parts of someone's body have many parts

e. if this someone wants it, all the parts on one side of one of these two parts can touch all the parts on one side of the other at the same time

f. because people's bodies have these two parts, people can do many things with many things as they want

g. because people's bodies have these two parts, people can touch many things as they want

[B] arms

a. two parts of someone's body

b. they are on two sides of the body

c. they are long[M]

d. the top $[\mathrm{M}]$ parts of these two parts are near the top[M] of the body

e. these two parts of someone's body can move as this someone wants

f. because people's bodies have these two parts, people can do many things with many things

\section{[C] legs}

a. two parts of someone's body

b. they are below all the other parts of the body

c. they are long[M]

d. these two parts of someone's body can move as this someone wants

e. because people's bodies have these two parts, people can move in many places as they want

[D] feet

a. two parts of someone's body

b. they are parts of the legs[M]

c. they are below all the other parts of the legs[M] 
d. the bottom[M] parts of these two parts of the body are flat $[\mathrm{M}]$

e. when people are moving somewhere for some time as people move somewhere when they are moving because they want to be somewhere else the bottom parts[M] of these two parts of the body touch the ground[M]

Comparing the four explications in this subsection we detect a certain recurring pattern, which can be summarized by means of the following rough headings: 1 . basic categorization, 2. location, 3. shape (or quasi-shape), and 4. function (or quasi-function).

The basic categorization can be either singular or dual ("one part of the body" or "two parts of the body); the location can be specified in terms of primes such as SIDE, ABOVE, BELOW, and NEAR; the shape (or 'quasi-shape') can be specified either in terms of simple molecules like "long", "round", and "flat" or indirectly via the prime TOUCH, and the function (or quasi-function) can be identified via primes like TOUCH and MOVE. In addition to these four parameters (roughly, basic categorization, location, shape and function), there are also, here and there, references to mobility and to further partonomic relations.

When we examine other groups of English body-part terms, we see similar recurring patterns, but we also see a good deal of variation.

\subsection{Head and associated parts}

$[\mathbf{E}]$ head

a. one part of someone's body

b. it is above all the other parts of the body

c. it is round $[\mathrm{M}]$

d. when someone thinks about something, something happens in this part of this someone's body

$[\mathbf{F}]$ neck

a. one part of someone's body

b. it is near the head[M]

c. it is below the head[M]

d. all the other parts of the body are below this part

e. when this part of someone's body moves, this someone's head[M] moves at the same time

$[\mathbf{G}]$ eyes

a. two parts of someone's body

b. they are on one side of the head[M]

c. because people's bodies have these two parts, people can see

$[\mathbf{H}]$ ears

a. two parts of someone's body

b. they are on two sides of the head[M]

c. because people's bodies have these two parts, people can hear 
[I] mouth

a. one part of someone's body

b. one part of this part of the body is on one side of the head[M]

c. another part of this part of the body is a place inside the head[M]

d. when people want things of some kinds to be inside the body, they do something with this part of the body

e. when people say something to other people, this part of the body moves

$[\mathbf{J}]$ nose

a. one part of someone's body

b. it is on one side of the head[M]

c. it is below the eyes[M], above the mouth[M]

d. if there are things of some kinds somewhere where people are, these people can feel something in this part of the body because of this

e. because of this, these people can know something about this place

\section{$[\mathbf{K}]$ tongue}

a. one part of someone's body

b. it is inside the mouth[M]

c. this part of someone's body can move as this someone wants

d. because people's bodies have this part, people can say many things to other people

Comparing the explications in this subsection we see that they all include components specifying the basic categorization, location, and something like function, but with the exception of head, do not include any references to shape. Since all the words in this group with the exception of head imply a very salient function one might speculate that it is this salience of the function which makes any references to shape unnecessary: the explications in this group "work" without any such references.

\subsection{Face and "places on the face" (forehead, chin, cheeks)}

[L] face

a. one part of someone's body

b. it is a place on one side of the head[M]

c. the eyes[M] are on this side

d. when other people see this part of someone's body they can know who this someone is

e. if other people see this part of someone's body when this someone feels something, they can know how this someone feels

$[\mathbf{M}]$ forehead

a. one part of someone's head[M]

b. it is a part of the face[M] 
c. this part of the face[M] is above all the other parts of the face[M]

d. it is a flat $[\mathrm{M}]$ place at the top[M] of the face[M]

\section{$[\mathbf{N}] \operatorname{chin}$}

a. one part of someone's head[M]

b. one part of it is a part of the face[M]

c. this part of the face[M] is below all the other parts of the face[M]

d. it is a place at the bottom[M] of the face[M]

e. another part of this part of the head[M] is below the face[M]

$[\mathbf{O}]$ cheeks

a. two parts of someone's face[M]

b. they are on two sides of the face[M]

c. they are two flat $[\mathrm{M}]$ places on two sides of the face[M]

Face implies a dual basic categorization: it is conceived of as, above all, a part of a person's body but also as a place on one side of a person's head. The other words in this subsection refer to some "parts of face" (cheeks) or to "parts of the head" which are also conceived of a "parts of the face" (forehead and chin). All the words in this group, including face, refer to certain "places". The general pattern which can be detected in this group includes in all cases basic categorization and location, in two cases shape (forehead and check), and in one case (face) something comparable to function (recognisability and communication of emotions).

8.5. The 'trunk" and its four main areas (chest, belly, back, backside)

$[\mathbf{P}]$ chest

a. one part of someone's body

b. it is a place on one side of the body

c. the face $[\mathrm{M}]$ is on this side

d. it is one of two big places on this side of the body

e. it is above the other big place

f. if someone is a $\operatorname{man}[\mathrm{M}]$ this place is flat $[\mathrm{M}]$

[Q] belly

a. one part of someone's body

b. it is a place on one side of the body

c. the face $[\mathrm{M}]$ is on this side

d. it is one of two big places on this side of the body

e. it is below the other big place

f. this place can be flat[M], this place can be $\operatorname{round}[\mathrm{M}]$ 


\section{$[\mathbf{R}]$ back}

a. one part of someone's body

b. it is a place on one side of the body

c. the face $[\mathrm{M}]$ is not on this side

d. it is one of two big places on this side of the body

e. it is above the other big place

f. this place is flat $[\mathrm{M}]$

[S] backside

a. one part of someone's body

b. it is a place on one side of the body

c. the face $[\mathrm{M}]$ is not on this side

d. it is one of two big places on this side of the body

e. it is below the other big place

f. this place has two parts

g. these two parts are round $[\mathrm{M}]$

The words explicated in this section reflect a model of the body which separates the "trunk" from the head (and neck), arms and legs, and which views that "trunk" as divided into four roughly comparable areas, two on one side of the body (the "front" side) and two on the opposite side.

On each side, the two areas are conceptually divided with reference to the body's ability to bend: the chest and the belly in the front and the back and the backside at the back. None of the four terms in question refers to anything like function, but they all specify a dual basic categorization ("part" and "place") as well as location and shape.

\section{6. "Joints"}

$[\mathbf{T}]$ elbow

a. one part of someone's $\operatorname{arm}[\mathrm{M}]$

b. it is a place on one side of the $\operatorname{arm}[\mathrm{M}]$

c. it is hard[M]

d. the $\operatorname{arm}[\mathrm{M}]$ has two long $[\mathrm{M}]$ parts

e. one of these two long[M] parts of the $\operatorname{arm}[\mathrm{M}]$ is on one side of this place

f. the other long $[\mathrm{M}]$ part of the $\operatorname{arm}[\mathrm{M}]$ is on the other side of this place

g. because people's arms[M] have this hard[M] part, one of the two long $[\mathrm{M}]$ parts can move when the other long $[\mathrm{M}]$ part is not moving

$[\mathbf{U}]$ knee

a. one part of someone's leg[M]

b. it is a round $[\mathrm{M}]$ place on one side of the $\operatorname{leg}[\mathrm{M}]$ 
c. it is a hard[M]

d. the leg[M] has two long $[\mathrm{M}]$ parts

e. one of these two long $[\mathrm{M}]$ parts is on one side of this place

f. the other of these two long $[\mathrm{M}]$ parts is on the other side of this place

g. because people's legs[M] have this hard $[\mathrm{M}]$ part, one of these two $\operatorname{long}[\mathrm{M}]$ parts can move when the other $\operatorname{long}[\mathrm{M}]$ part is not moving

$[$ V] wrist

a. one part of someone's arm[M]

b. it is a place near the hand[M] on one side of the hand $[\mathrm{M}]$

c. because people's arms[M] have this part near the hands[M], the hands $[\mathrm{M}]$ can move when the other parts of the arms[M] are not moving

$[\mathbf{W}]$ ankle

a. one part of someone's leg[M]

b. it is a place near the foot $[\mathrm{M}]$, above the foot $[\mathrm{M}]$

c. because people's legs[M] have this part, the feet $[\mathrm{M}]$ can move when the other parts of the legs $[\mathrm{M}]$ are not moving

The words characterized here as "joints" also reflect dual categorization: one in terms of parts of certain parts of the body ('arms' and 'legs'), and another, in terms of places. They all specify location and function, and they all include some references to shape. For all four, function is specified in terms of the ability of certain parts of the relevant parts of the body to move.

\subsection{Testing the cross-linguistic translatability of explications}

To show that explications of this kind are indeed language-independent and can be rendered in languages as distant from English as the Papuan languages referred to in the Special Issue, I will adduce here the counterparts of the explications of 'head' and 'eyes' in the Papuan language Koromu, provided by a long-term student of the language, Carol Priestley. These explications are doubly instructive, in that they illustrate both the cross-linguistic translatability of NSM explications and also various problems that such a process of translation may involve.

\subsubsection{A hypothetical Koromu version of the explication of the English word 'head'}

turupu ('head')

mete mo nupu nupu mena

mo aterei mo tomo nupu mena

$\mathrm{u}$ warimimo

ato urunuante, mo mo orupa, na airea 
With interlinear glosses

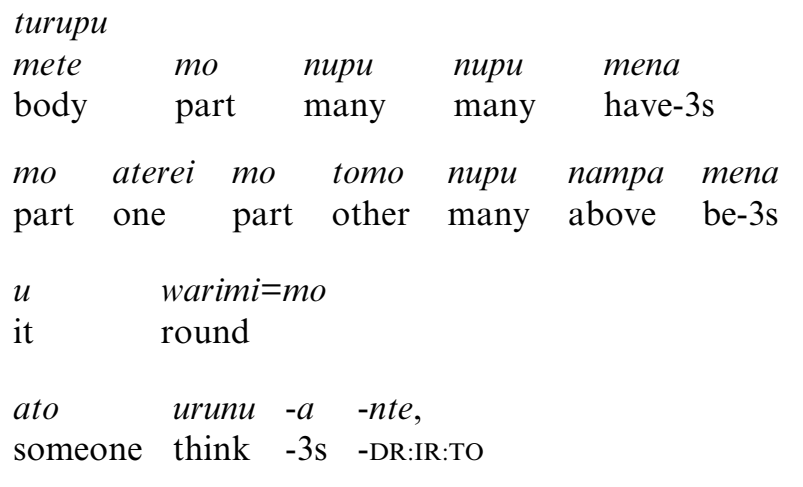

$\begin{array}{llllll}\text { mo } & \text { mo } & \text { orupa, } & \text { na } & \text { aire } & -a \\ \text { this } & \text { part } & \text { inside } & \text { something } & \text { happen } & -3 \mathrm{~s}\end{array}$

\title{
English translation
}

the body has many parts

one part is above all the other parts

it is round

when someone thinks about something, something happens in this part ${ }^{9}$

8.7.2. A hypothetical Koromu version of the explication of the English word 'eyes'

\author{
ami ('eyes') \\ mete mo nupu nupu mena \\ ami mete asao \\ u turupu asao \\ $\mathrm{u}$ aire \\ mo aire sei aharopu werepura
}

With interlinear glosses

ami 'eyes'

$\begin{array}{lllll}\text { mete } & \text { mo } & \text { nupu } & \text { nupu } & \text { mena } \\ \text { body } & \text { part } & \text { many } & \text { many } & \text { have }\end{array}$

\footnotetext{
${ }^{9}$ Note mena is 'have' when it occurs with two juxtaposed noun phrases in the first line and 'be' with a subject and a postpositional phrase in the second line.

With regard to the last component, Priestley states that her translation of it is tentative and that she has not been able to check it with a native speaker, and she offers an alternative phrasing of the second part of the last component, with a different exponent of PART (asao):

\begin{tabular}{|c|c|c|c|c|}
\hline $\begin{array}{l}\text { mo } \\
\text { this }\end{array}$ & $\begin{array}{l}\text { asao } \\
\text { part }\end{array}$ & $\begin{array}{l}\text { orupa } \\
\text { inside }\end{array}$ & $\begin{array}{l}n a \\
\text { something }\end{array}$ & $\begin{array}{l}\text { aire- } a \text {. } \\
\text { happen-3s }\end{array}$ \\
\hline
\end{tabular}
}




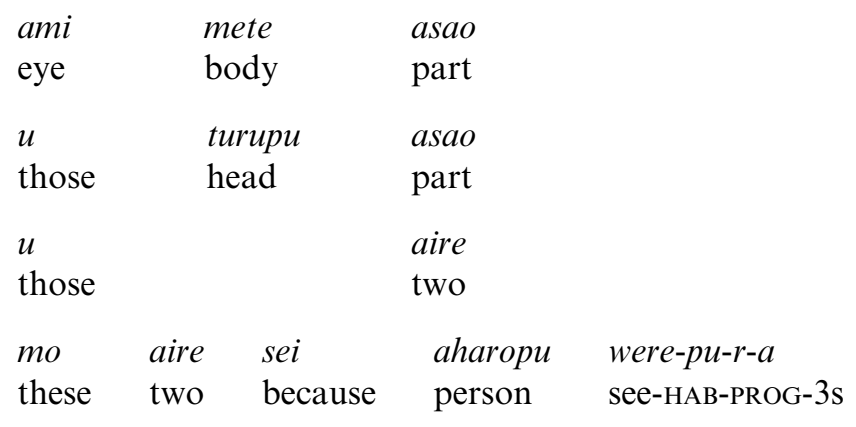

\section{English translation \\ the body has many parts \\ the eyes are parts of the body \\ they are parts of the head \\ they are two \\ because of these two a person can see}

As these glosses show, in one context ("the body has many parts"), the concept of PART is rendered in Koromu by the word mo, whereas in another ("the eyes are parts of the body") it is rendered with the word asao. This is what is known in NSM as "allolexy": two different words (or morphemes) may function in different contexts as two lexical variants of the same simple meaning.

Priestley's Koromu examples also illustrate the problem of polysemy in identifying semantic primes: the element $m o$, which in the explication given here clearly means PART, in other contexts can mean 'this' or 'here'.

The process of constructing explications and testing them cross-linguistically often generates new questions and new hypotheses. This is how semantics works in the NSM approach: through hypotheses and experimentation.

Let me close this section by formulating a general methodological principle: semantics begins at home. If we want to understand indigenous meanings in a particular semantic domain - be it colour, physical activities, body parts, or whatever - we need to start by exploring our own meanings in this domain. For example, if we as native or native-like speakers of English do not know what words like arms, legs or feet mean in English, it is an illusion to think that we can find out what their nearest counterparts in an "exotic" language somewhere in the Pacific may mean. In particular, it is an illusion to imagine that we can establish what those indigenous meanings are by observing the denotata in the external world, by video-recording the behaviour of the speakers, or by showing indigenous consultants some physical objects (especially culturally alien ones such as Munsell chips, diagrams, pictures of naked bodies with or without fig leaves, and so on), and recording their responses to such objects.

To figure out what body-part terms in a far-away language mean we must be able to formulate semantic hypotheses and to test them. The best starting point for such hypotheses is a set of plausible explications of comparable terms in our own language, and especially in English, given that English is now the linguistic lingua franca and the only language available to all linguists as a shared testing ground for semantic hypotheses. 


\section{Comparing ethnoanatomies through NSM}

The use of the natural semantic metalanguage based on universal human concepts allows us not only to articulate indigenous meanings but also to compare them, without any ethnocentric bias. Any comparison requires a tertium comparationis, a common measure, and the NSM with its 65 or so primes gives us such a common measure. As the analysis so far illustrates, in the area of ethnoanatomy the most frequently recurring primes include BODY, PART, TWO, THIS, OTHER, LIKE, ABOVE, BELOW, ON . . . SIDE, INSIDE, NEAR, PLACE, and MOVE. Recurring molecules include 'top' and 'bottom', and 'long', 'round' and 'flat'. As we will see below, one other molecule which can play a role in this domain is 'the ground'.

\subsection{English 'Feet' vs. Polish 'stopy'}

As mentioned earlier, the English word feet differs from the Polish word stopy in the basic categorization: 'feet' are, like hands, "two parts of the body", whereas stopa is "one part of a noga (roughly, leg)". In Polish, stopa (singular) is, conceptually, like udo 'thigh', kolano 'knee' and łydka 'lower leg': all these are "parts of a person's noga ([one] leg)". In English, on the other hand, the feet (dual) are more salient than thigh, ankle or even knee, and often collocate with hands, another word for "two parts of the body": hands and feet. In Polish, ręce (hands/arms) does not collocate with stopy, but only with nogi: ręce i nogi, 'ręce and (roughly), legs'.

\section{feet (English)}

a. two parts of someone's body

b. they are parts of the legs[M]

c. they are below all the other parts of the legs[M]

d. the bottom[M] parts of these parts of the legs[M] are flat $[\mathrm{M}]$

e. when people move in many places as people move somewhere when they move because they want to be somewhere else the bottom[M] parts of these two parts of the body touch the ground[M]

stopa (Polish)

a. -..-.-.--

b. one part of someone's noga[M]

c. it is below all the other parts of the $\operatorname{nog} a[\mathrm{M}]$

d. the bottom[M] part of this part of the $\operatorname{nog} a[\mathrm{M}]$ is flat $[\mathrm{M}]$

e. when people move in many places as people move somewhere when they move because they want to be somewhere else the bottom[M] part of this part of the $\operatorname{nog} a[\mathrm{M}]$ touches the ground[M]

Apart from the first component of feet (a), which is simply absent in the explication of stopa, all the other components are essentially the same, except that in the case of feet, they are dual ("they", i.e., "these two parts"), whereas in the case of stopa, they are singular ("it", i.e., "this one part). 
Explicating stopa in the singular and feet in the plural is not a matter of arbitrary decision, but of the internal logic of these explications. The test lies in producing coherent explications. There is only one way to determine what is conceptually more basic, 'elbow' or 'elbows', 'knee' or 'knees', 'ankle' or 'ankles': to try both ways of explicating these concepts and to see which of these two ways "works". It is on this basis that, having tried both ways, I have explicated here 'hands', 'feet', 'arms' and 'legs' as, basically, dual concepts, and 'elbow', 'knee' and 'ankle', as well as 'stopa', as basically singular ones.

As the two explications in this section illustrate, comparing ethnoanatomical concepts is not as straightforward as comparing concepts in those domains (e.g., emotions or speech acts) which can be explicated directly through the universal semantic primes. Unlike those other concepts, body-part terms often require the use of semantic molecules, and not only universal or near-universal ones like 'top' and 'bottom', but also of language-specific ones like 'legs' and 'nogi'.

To achieve full comparability we need to explicate such language-specific molecules, reducing them, too, to different configurations of the same universal primes. As illustrated throughout this paper, this can be done too, but the need to go through some language-specific molecules means that the comparison may have to be carried out in two or three steps.

\subsection{English 'Shoulders' vs. Polish 'ramiona'}

As mentioned earlier, the Polish word ramiona (singular ramie) has three distinct meanings in Polish: it can refer either to the places on two sides of the neck, above the arms, or to the arms, or to the upper arms. The first one of these three meanings $\left(\right.$ ramiona $\left._{1}\right)$ is roughly similar to that of the English shoulders, but only roughly: one cannot have in Polish a "dislocated ramie" as one can have a "dislocated shoulder" in English, because the Polish ramie (in the relevant sense) does not include the top of the person's arm, that is, the very part of the shoulder which could become 'dislocated'. In this respect, the Polish ramiona $_{1}$ appears to be similar to the Lao counterpart of shoulders, as described by Enfield (2006a, p. 187): "flattish (i.e. horizontal) region between the base of the neck and the shoulder point".

The two meanings, that of the English shoulders and that of the Polish ramiona 1 , can be compared by means of the following NSM explications:

shoulders (English)

a. two parts of someone's body

b. they are two places near the neck[M] on two sides of the neck[M]

c. the top $[\mathrm{M}]$ parts of the $\operatorname{arms}_{1}[\mathrm{M}]$ are parts of these two parts of the body

ramiona $_{1}($ Polish $)$

a. two parts of someone's body

b. they are two places near the neck[M] on two sides of the neck[M]

c. they are above the $\operatorname{rece}_{2}[\mathrm{M}]$ (roughly, $\operatorname{arms}_{1}[\mathrm{M}]$ )

Strictly speaking, the explications of shoulders and ramiona given above cannot be compared as easily and as transparently as those of feet and stopa or those of thumb and duzy 
palec. Those four earlier explications were constructed of identical primes and identical molecules. The explication of ramiona, on the other hand, includes the Polish molecule rece $_{2}[\mathrm{M}]$, which while close, is not identical to the English molecule $\operatorname{arms}[\mathrm{M}]$ used in the explication of shoulders. To achieve complete comparability we need to decompose these language-specific molecules in terms of universal semantic primes. This is the task to which I will now turn.

\subsection{More on English 'arms' vs. Polish 'rece,}

The differences between the English word arms and its closest Polish counterpart rece 2 have already been discussed. However, since both rece and arms are polysemous, to clearly compare these two words we need to analyse their meanings more fully and more systematically.

As noted earlier, arms can be conjoined in English with legs (arms and legs) and it can also be conjoined with hands (hands and arms). In the phrase arms and legs, the word arms refers to, so to speak, a person's two "upper limbs". I will call this meaning $a r m s_{1}$. In the phrase hands and arms, on the other hand, arms refers, so to speak, to the "upper limbs minus hands". I will call this second meaning arms $_{2}$.

Evidence suggests that $a r m s_{1}$ has a dual semantic structure ("two parts of the body...") but that $\mathrm{arms}_{2}$ does not: while the concept of an $\mathrm{arm}_{1}$ in the singular is based on the concept of $a r m s_{1}$ in the plural, the concept of $a r m_{2}$ is derived form the concept of $a r m_{1}$, not from the concept $a_{r m s}$. This rather confusing picture of the semantic relationships between the words in question can be schematically represented as follows: $\operatorname{arms}_{1} \rightarrow$ arm $_{1}$; $\mathrm{arm}_{1} \rightarrow \mathrm{arm}_{2} ; \mathrm{arm}_{2} \rightarrow \mathrm{arms}_{2}$.

As for the Polish "upper-limb" word, rece (plural), it too is a dual concept, like arms , $_{2}$ and the singular form ręka is semantically derived from it: rece $e_{2} \rightarrow r e k a_{1}$.

A full justification of these claims would take more space than is available in the confines of this paper. What I can do here, however, is to show that they provide a sufficient basis for a coherent set of NSM explications. The first point to note is that $\operatorname{arm}_{1}$ (in the singular) is defined via $\operatorname{arms}_{1}$ (in the plural) and that ręka (in the singular) is defined

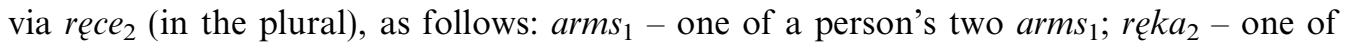
a person's two rece . $_{2}$

$\operatorname{arms}_{1}$ (as in arms and legs)

a. two parts of someone's body

b. they are on two sides of the body

c. they are long[M]

$\mathrm{d}$. the top $[\mathrm{M}]$ parts of these two parts of the body are near the top[M] of the body

e. these two parts of someone's body can move as this someone wants

f. because people's bodies have these two parts, people can do many things with many things

rece $_{2}$

a. two parts of someone's body

b. they are on two sides of the body 
c. they are long[M] [podtuzine $[\mathrm{M}]]$

d. -...-.

e. the hands $[\mathrm{M}]$ are parts of these two parts of the body

f. these two parts of someone's body can move as this someone wants

g. because people's bodies have these two parts, people can do many things with many things

The two differences between 'arms' ${ }_{1}$ and 'recee' as explicated here lie in the "top-heavy" component assigned here to 'arms,' but not to 'recee ${ }_{2}$, and in the "hands-oriented" component assigned to rece $e_{2}$ but not to $\operatorname{arms}_{1}$ : the explication of $\operatorname{arms}_{1}$ includes component (d) "the top $[\mathrm{M}]$ parts of these two parts are near the top[M] of the body", which is missing from the explication of rece $e_{2}$, and the explication of rece includes component (e) "the rece $_{1}$ are parts of these two parts of the body", which is missing from the explication of arms . $_{1}$

For the sake of completeness, I will explicate also $\operatorname{arm}_{2}$.

$\operatorname{arm}_{2}$

a. one part of someone's $\operatorname{arm}_{1}[\mathrm{M}]$

b. it is one of two parts of the $\operatorname{arm}_{1}[\mathrm{M}]$

c. the hand $[\mathrm{M}]$ is one of these two parts

d. this part $\left[\mathrm{arm}_{2}\right]$ is the other part

9.4. English toes vs. Polish palce u nóg (lit.'fingers at legs')

toes (English)

a. many parts of someone's feet[M]

b. they are small

c. they are like fingers[M]

d. these parts of someone's feet[M] can move if this someone wants

palce u nóg (lit. 'fingers at legs', Polish)

a. many parts of someone's nogi[M]

b. they are part of the bottom[M] part of the $\operatorname{nog} i[\mathrm{M}]$

c. they are small

d. they are like fingers[M] [palce, $\mathrm{M}]$

e. these parts of someone's nogi[M] can move if this someone wants

While in both cases the basic categorization involves multiple parts of two parts taken as a unit, in the English concept these "two parts" thought of a unit are the 'feet', whereas in the Polish one, they are 'nogi' (roughly, legs). The second difference follows directly from the first one: the explication of the Polish concept includes one further component (b), referring to the bottom parts of the "legs", for which there is no need in the explication of the English one, given that this information is already included in the first component (a) of that explication. 


\subsection{English 'thumb’ vs. Polish 'duży palec'}

As the expression duży palec (lit. 'big finger', singular) suggests, a Polish 'duży palec' is seen as definitely one of a person's palce (plural) 'fingers', whether an English 'thumb' appears to be conceptually somewhat more distant from 'fingers'. When asked "how many fingers does a person have?" some English native speakers reply "four fingers and a thumb", whereas in Polish, the only conceivable answer to a similar question about palce would be "five". This difference in the conceptual distance from the other 'fingers' can be reflected in the following explications of thumb and duzy palec (note, in particular, the different phrasing of components (a) and (b)):

\section{thumb (English)}

a. one part of someone's hand[M]

b. it is on one side of all the other parts of the hand[M]

c. it can move when the other parts of the hand $[\mathrm{M}]$ are not moving

d. it is one of the fingers[M]

e. it is not like the other fingers[M]

f. it is big

du̇y palec (lit. 'big finger', Polish)

a. one of someone's fingers[M] [palce, $\mathrm{M}]$

b. it is on one side of all the other fingers[M]

c. it can move when the other fingers[M] are not moving

d. it is not like the other fingers[M]

e. it is big

\subsection{The heuristic value of label-sharing}

Does it matter whether two body-part concepts share one label or have a separate label each? Explorations in cross-linguistic semantics such as those presented here suggest that often it does matter, in the following sense: if in language A two body-part concepts share (or partially share) a label and in language B they do not, the chances are that the labelsharing concepts in language A will be semantically closer than the non-label-sharing concepts in language B.

For example, as shown earlier, the Polish concept of ' recee $_{2}$ ' (roughly, arms) is closer to the concept of 'rece ${ }_{1}$ ' ('hands') than the English concept of 'arms,' is to the concept of 'hands'. Similarly, the Polish concept of 'duży palec' (lit. 'big finger') is closer to the concept of 'palce' ('fingers') than the concept of 'thumb' is to the concept of 'fingers', and the Polish concept of 'palce u nogi' (lit. 'fingers at leg') is closer to the concept of 'palce' ('fingers') than the concept of 'toes' is to the concept of 'fingers'.

Thus, I am not claiming that features of "labelling" have no significance at all. On the contrary, even aside from their "resonance" (cf. Goddard, 1994, 2002a), they can often provide good heuristics in semantic analysis. They can never, however, provide conclusive arguments: features of lexical form can also be misleading, and to discover when and how 
they are illuminating and when and how they are misleading, we need careful semantic analysis based on semantic, not formal, evidence.

For example, the fact that the Polish words rzesy ('eyelashes') and brwi ('eyebrows') are not formally related to the word oczy ('eyes') does not establish that the concepts of 'eyelashes' and 'eyebrows' are closer to the concept of 'eyes' than the concepts of 'rzesy' and 'brwi' are to the concept of 'oczy'.

Principles like "one word one meaning" or "two words two meanings" are certainly wrong, and features of form such as partial formal overlaps can only be regarded as potential clues to semantic analysis, not as solid evidence.

\section{Semantic universals of body-part terminology}

The clearest and most important universal of the domain of the human body is the concept of 'body' itself - a point recognized in two classic papers on the subject, one by Brown (1976) and one by Andersen (1978). In his paper entitled "General principles of human anatomical partonomy" Brown (1976, p. 404) put it as follows: "The Whole, i.e. the human body, is labelled in all human anatomical partonomies". Andersen (1978, p. 353) concurred: "the BODY is labelled in all body-part partonomies".

As noted at the outset, this important semantic universal was disputed in the subsequent literature, including the 2006 Special Issue, mainly because the polysemy of the word for BODY in many languages was often not recognized, and also because loan words were often discounted as legitimate exponents of indigenous concepts. Once the issues of polysemy and loan words have been clarified, however, it becomes clear that the concept of 'body' is indeed a human universal.

A second universal which I have posited in this paper, the presence of a lexically embodied concept of 'hands', was not recognized by either Brown (1976) or Andersen (1978), although it was, one might say, adumbrated by these authors. Thus, one of Brown's "general principles" read: "The parton /arm (and hand)/ is labelled in all human anatomical partonomies" (p. 405). A similar equivocation in regard to 'hands' can be seen in Andersen's list of what she called "universals of categorization for the domain of human body-parts": "The upper limb, ARM (and HAND) is named by a distinct term in all languages" (p. 352). Thus, both Brown and Andersen emphasized the universality of 'arm' or 'arm/hand', but not the universality of 'hands' as such.

As discussed earlier, the emphasis on "a distinct term" clouds the issue as far as human conceptualization of the body parts is concerned: both the words for 'body' and the word for 'hands' can be polysemous (as can of course be the word for 'part'), but this should not prevent us from recognizing the universality of these concepts as distinct word-meanings.

Several contributors to the Special Issue assert that this or that language "doesn't have a word for hand", but even they stop short of explicitly presenting the absence of a separate word for 'hand' as a conceptual gap. As I have argued in this paper, without recognizing the presence of 'hands' as a universal semantic molecule, virtually no other body-part concepts could be explicated at all: all other body-part concepts refer either directly or indirectly to shape, and shape concepts are based on the concept of 'hands'.

A third semantic universal which I think can be posited with some confidence is a lexically embodied concept of 'head' (with or without a THINK-related component), which, as the explications in Section 7 above make clear, underlies also concepts like 'eyes', 'ears', 'mouth' and 'nose'. 
Brown (1976, p. 405) says of 'head' that it 'is apparently always labelled and always by an unanalysable primary lexeme", and Andersen (1978, p. 353), that "every language includes a term for HEAD in its lexical field of body parts". Since concepts like 'eyes', 'mouth' and 'nose' depend in their meaning on the concept 'head', if some languages did not have a word for 'head', they would not have concepts comparable to 'eyes', 'ears', 'mouth' and 'nose' either - a scenario which in the light of available evidence can I think be discounted with reasonable confidence.

As noted earlier, Burenhult (2006, p. 169) suggests that Jahai may not have a word for 'head': "As far as head is concerned, the Jahai equivalent $k u y$ appears to denote only that part of the head which is covered by the head-hair. In the colouring task, for example, Jahai consultants uniformly exclude the face (usually also the forehead) when indicating kuy". In my view, the consultants' reluctance to colour in the face shows, above all, how unreliable the colouring task is in establishing indigenous meanings.

As soon as the challenge of articulating the indigenous meaning is faced, it becomes clear how improbable the suggestion is that kuy means anything other than 'head': if kuy means 'head', it can be explicated in Jahai itself in the way the English head has been explicated in Section 8 ("one part of the body - it is above all the other parts of the body it is round"10). But how could one explicate in Jahai a word which meant, roughly, "head minus face", or "head minus the parts on one side of the head", if the language did not have a word for 'head'? (Not to mention the fact that according to Burenhult, Jahai has no word for 'face' either.)

In a sense, in the light of the available evidence it could also be suggested that not only 'head' but also 'eyes', 'ears', 'mouth' and 'nose' are conceptual universals. Nonetheless, I would not hypothesise at this stage that either 'head' or the main concepts based on it ('eyes', 'ears', 'mouth' and 'nose') are absolute semantic universals, because even apart from a hypothetical 'think' component, the concept of 'head' appears to be partly based on shape ("it is round"), and shape-concepts can differ somewhat in different languages.

One could of course hypothesise that in some languages the word for 'head' includes only two semantic components (1. one part of the body, 2. it is above all the other parts of the body), without any reference to shape (or to thinking). However, given widespread polysemies of the word for 'head', which is often extended to various other "round" things, this is unlikely. Furthermore, speakers need to distinguish the concept of 'head' from the concept of 'the top of the body', and for this, some reference to the shape of the head is necessary. It is also worth recalling that as noted in the quote from Morrison and Tversky adduced earlier, young children all over the world depict the human head in their drawings as something round, just as they depict arms and legs as sticks.

While the shape-triad: 'long', 'round' and 'flat' is often assumed to be universal (cf., e.g., Friedrich, 1970), the semantic details of such concepts can in fact be language-specific (cf. Wierzbicka, 2006b). Consequently, if the words for 'head' in different languages include a reference to a "round" shape, the meaning of these words would differ in details, too - and so would the meanings of the words for 'eyes', 'ears', 'mouth' and 'nose'.

Thus, I submit that while 'body' and 'hands' are absolute lexico-semantic universals, 'head', 'eyes', 'ears', 'mouth' and 'nose' are probably approximate universals - not in

\footnotetext{
${ }^{10}$ Whether or not a further component referring to 'thinking' is encoded in the word for 'head' in a particular language is always a matter for investigation.
} 
the sense that some languages do not have such concepts at all but in the sense that for these concepts, some semantic details may be different in different languages. Nonetheless, I would hypothesize that, apart from such details, the semantic core of the concepts 'head', 'eye', 'ears', 'mouth' and 'nose' as explicated in Section 7 is shared by all languages without exception.

As for the "general principles of human anatomical partonomy" (to use Brown's phrase), the two main principles recognized by both Brown and Andersen are those of partonomic structure itself and of hierarchical organization. Despite the doubts raised in the Special Issue about both BODY and PART, the semantic explorations undertaken in the NSM framework confirm the fundamental role of the notion of 'part of the body' as a universal organizing principle in all ethnoanatomies.

They also confirm the tenet of hierarchical organization of this domain, in the following sense: evidence suggests that while some parts of the body are conceptualized essentially as "a part of the body" (or "two parts of the body"), others are conceptualized as, essentially, "a part of a part of the body". For example, in English, head is 'a part of the body', whereas forehead is 'a part of the head'.

On the other hand, semantic explorations of the domain in question do not support Andersen's hypothesis that partonomies of human body parts may contain as many as five or six levels, and I see no semantic justification for schematas such as the following one (Andersen, 1978, p. 347):

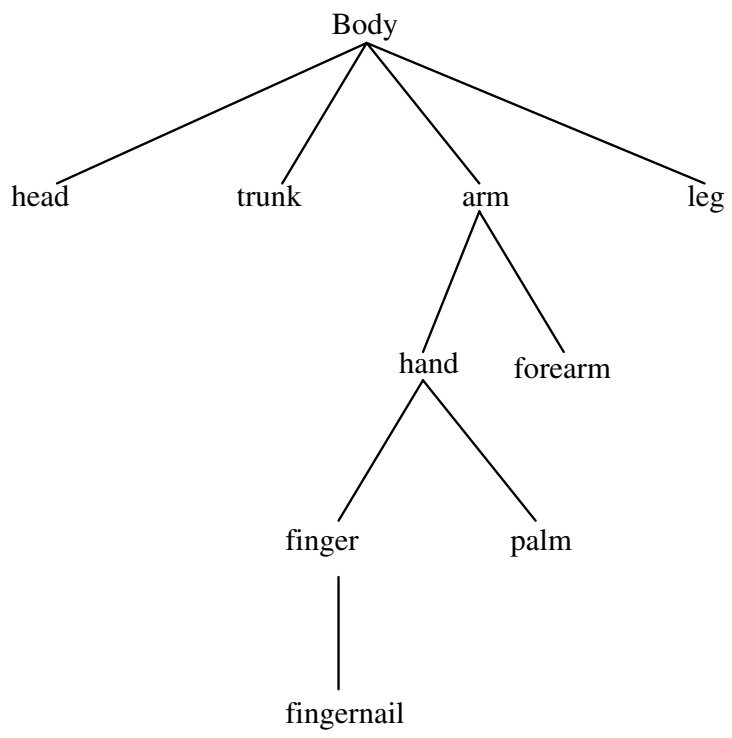

Apart from the fact that this diagram fails to recognize the basic duality of the concept 'hands', it misrepresents the conceptual relation between 'hands', 'arms' and 'body'. As argued in this paper, 'hands' are in English 'two parts of the body', not 'two parts of the arms'. Furthermore, the challenge of explicating 'finger' shows that a 'finger' is not 'one part of the hand', but rather, 'fingers' (in the plural) are "many parts of the hands" (in the plural). 'Trunk', which I have not discussed in this paper, is not conceptualized as 'a 
part of the body', on a par with 'head', 'arms', and 'legs'; it is a more complex concept, which refers to 'head', 'arms' and 'legs' as well as to the body as a whole.

A third universal principle, which in contrast to the other two does not appear to have been recognized in the earlier literature on body-part semantics, is the principle of duality: as argued throughout this paper, several body-part concepts can only be explicated as "two parts of the body", not as "one part of the body". For example, a 'hand' is, semantically, "one of the hands", and an 'eye' is, semantically, "one of the eyes", where "hands' and 'eyes' are explicated as "two parts of the body". (cf. Wierzbicka, 1980, p. 80, 84).

A fourth universal organizing principle reflected in the explications developed here can be called the principle of "topographic configurations", which can be illustrated with the following set of partial explications:

head- one part of someone's body

it is above all the other parts of the body

neck- one part of someone's body

it is near the head[M]

it is below the head[M]

eyes- $\quad$ two parts of someone's body

they are on one side of the head[M]

ears- $\quad$ two parts of someone's body

they are on two sides of the head[M]

legs- $\quad$ two parts of someone's body

they are below all the other parts of the body

Enfield (2006b, p. 198) made the following general observation: "it is possible that most if not all relations between body parts are expressible in terms of location". While the main illustration he chose for this suggestion - the putative "location relationship" between 'hand' and 'arm' - was, as I have argued, unfortunate, the general point is in my view right: 'location' of various parts does play an important role in the conceptualization of the body. Furthermore, as Enfield put it, "Calling the whole system a 'partonomy' attributes greater centrality to the part/whole relation that is warranted" (p. 199). Although the Special Issue errs, in my view, in trying to undermine the universality of the elementary concepts 'body' and 'part' and of the complex concept 'part of the body', partonomies were indeed overemphasized in earlier literature, and various multi-level partonomies were often posited without sufficient justification, while the "topography of the body" was largely ignored.

I welcome these suggestions, which in fact converge with those made in my Semantic Primitives (1972) and developed into a system of definitions in my Lingua Mentalis (1980). For example, in Semantic Primitives I wrote (1972, pp. 27-28) "In the case of parts of the body (...) it is sometime necessary to explicate anatomically, sometimes functionally and sometimes "topographically": elbow - the part of the arm where it bends, knee - the part of the leg where it bends, thigh - the part of the leg above the knee."

Generally speaking, while the conceptualizations of the human body reflected in different languages can be justifiably described as partonomies, these partonomies are much 
more "shallow" than suggested in Brown (1976) and Andersen (1978). As the explications presented in Section 8 argue, most lexically recognized parts of the body are conceptualized as just that: "parts of the body", not as "parts of some parts of some parts (of some parts ...) of the body".

Certain parts of the body are indeed conceptualized as 'parts of some parts of the body', for example, 'thigh' is, arguably, conceptualized as 'one part of the leg', not as 'one part of the body', but there are no named parts of 'thigh' in English (so there is no third level of partonomy here). It is true that 'feet' do have named parts ('heels' and perhaps 'toes'), but then 'feet' themselves are conceptualized as 'parts of the body', not as 'parts of the legs'. A third level of partonomy below 'body' is not impossible but it appears to be rare. For example, according to the explications proposed here, 'cheeks' are 'two parts of the face', 'face' is 'one part of the head', and 'head' is 'one part of the body'; but there are not many cases of this kind in English.

The fifth universal principle in the semantics of the body is the principle of internal logic'. As I sought to demonstrate in my Lexicography and Conceptual Analysis (Wierzbicka, 1985), words for artifacts (like cup and $m u g$ ) and words for natural kinds (like cat and mouse) "make sense" because they link perceptual features with, broadly speaking, functional ones. Mutatis mutandis, the same applies to body-part concepts as explicated here. For example, the explications of 'legs' and 'feet' proposed here refer not only to shape and position, but also, implicitly, to walking, and the explication of 'mouth', to eating and speaking.

Concepts like 'forehead', 'cheeks' and 'chin' do not refer to any functions, but then they are presented as 'places', and the same applies to 'chest' and 'belly' (two "big places" on that side of the body where the face is) and to 'back' and 'backside' (two "big places" on the opposite side of the body). In fact, the model of the body reflected in the explications proposed here sets apart the head, the limbs and the neck from the "bulk of the body", which, as noted earlier, is divided, symmetrically, into four areas, two at the front ('chest' and 'belly') and two at the back ('back' and 'backside').

The fact that some parts of the body are seen as "areas" can be regarded as a sixth general principle in the conceptual organization of the whole field. (On this point, cf. Enfield, 2006a, p. 154). As the explications presented here suggest, some parts of the body appear to be conceptually singled out from the whole because they have a salient function. Thus, 'eyes' are associated with seeing, 'ears', with hearing', 'nose', with smelling, 'mouth' with eating and speaking, 'legs' and 'feet', with walking, 'hands' and 'arms', with manipulating things, 'neck', with enabling the head to move, 'knees' and 'ankles', with facilitating the movements of certain parts of the legs, and so on. (The same applies of course to various words for the genitalia and for some internal body-part concepts, which have not been discussed here.) By contrast, 'forehead', 'cheeks' and 'chin' do not seem to be associated with any identifiable salient functions, and neither are 'chest', 'belly', 'back' and 'backside' and it is precisely these parts of the body which appear to be conceptualized as areas ('places').

The generalization emerging from these observations is that parts of the body attract sufficient attention to become conceptualized as distinct "body-parts" and named either because they have an identifiable function or because they are perceptually salient as "areas" - usually, but not necessarily, because they are "big areas", as in the case of 'chest', 'belly', 'back' and 'backside'. If this is true then there is a certain logic in this, 
too: a named "body-part" is evidently conceptually salient, and this salience is linked either with certain identifiable functions or with a salient location and shape. ${ }^{11}$

For example, surveys of body-part terminologies in different languages suggest that the area of the body between the armpit and the hip is usually not named. Presumably, this is not an accident but a reflection of the fact that this area is neither associated with any clearly defined function nor perceptually striking. By contrast, 'chest', 'belly', 'back' and 'backside' attract attention as two large areas ('big places') on one side of the body which can be clearly seen and which are conceptually divided from one another by the arms and by the body's ability to bend at the waist.

This conceptual division of the "trunk" into two sides (front and back), with two "big places" on each side, brings me to the seventh organizational principle of "bodily semantics" which I want to discuss in this paper: the concomitant use of the body as a frame of reference for human orientation in space.

In the explications of 'chest', 'belly', 'back' and 'backside' proposed here I have used 'face' as a point of reference to distinguish the two opposite sides: 'the front of the body' and 'the back of the body'. At the same time, I have not posited 'face' as a universal human concept. For example, according to Burenhult (2006, p. 167) there is no Jahai term for 'face', and in this case the claim is plausible: bilingual consultants "maintain that there is no word for what Malay refer to as muka 'face"". But if 'face' is not universal, what could provide a universal reference point for the notions of 'front' and 'back'?

According to Levinson, the notions of 'front' and 'back' are in fact not universal: 'Tenejapan Tzeltal uses no relative frame of reference, and has no 'left', 'right', 'front', 'back' terms for spatial reference in that frame" (1996, p. 376). As I pointed out in my Semantics: Primes and Universals (Wierzbicka, 1996, pp. 93-95), however, Haviland's (1979, p. 179) basic vocabulary list for Guugu Yimithirr does in fact include a word glossed as 'in front'. I have also pointed out that, like most (if not all) languages, Tzeltal has a word for 'straight"12 (as in "a straight path" or "going straight ahead") and I have sought to demonstrate that the concept of 'straight' is built on the concept of 'in front of': roughly, if I want to go 'straight,' or 'straight ahead', I want to go towards some place which is "in front of me" (Wierzbicka, 2006a).

For a language like English, the notion of 'in front of' can be interpreted as 'on the side of the body where the face is' (cf. Wierzbicka, 1996, p. 93-95). But what could the equivalent of 'in front of' mean in a language which does not have a word for 'face'? After a moment's reflection, the answer seems obvious: in such a language, 'in front of (someone)' would presumably mean 'on the side of the body where the eyes are'.

If the concept of 'face' is not universal, then the concepts of 'chest', 'belly', 'back' and 'backside' are not universal either, but it is easy to see what the nearest counterpart of, say, 'back' in a language without the concept of 'face' might be: it could be almost identical to

\footnotetext{
11 Among those body-part terms which are conceived of as places, some (the "joints") do refer to a function, but many do not. Those terms which are not conceived of as places and which nonetheless do not refer to a function appear to include mainly those which are thought of as "parts of some parts of the body", rather than as "parts of the body", for example thigh and calf in English.

12 Neither this critique of Levinson's claims about universals of space nor the challenge in Goddard (DATE) was ever answered. Instead, in his 2003 book "Space in language and cognition: Explorations in cognitive diversity" he dismissed the NSM theory in general with one word: "controversial" - rather like the politician who seeks to dismiss an inconvenient report by calling it "flawed" and ignoring the substance.
} 
the English concept of 'back' (as explicated in Section 8) except that component (d) "the face is not on this side" would be replaced with $\left(\mathrm{d}^{\prime}\right)$ "the eyes are not on this side".

The choice of 'eyes' rather than 'mouth' or 'nose' as a likely reference point for the 'front/back' axis of the body is not arbitrary: it is the viewpoint which matters. Levinson (1996, p. 369) contrasts the conceptualization of space reflected in English, where "the primary coordinate system is based on the viewer", with the "Tzeltal spatial description, in which (...) the human frames play almost no part in the actual concepts employed". English is, in this view, an example of a "relative system of spatial description", which is not universal: "Relative systems of spatial description build in a viewpoint and are thus essentially 'subjective", (1996, p. 370).

As I have argued in Wierzbicka (2006a), however, such claims seem to be going too far. A 'viewpoint' is inherent in the concept 'in front of', in either of its two versions (roughly, 'on the side of the body where the face is' and 'on the side of the body where the eyes are'). A 'viewpoint' is also inherent in the conceptualization of the human body which divides the bulk of the body into four areas (roughly, chest, belly, back, and backside), all of them defined with reference to either the face or the eyes. Clearly, the 'front' side of the body is privileged in such a system. A 'viewpoint' is also inherent in the meaning of words designating basic human activities such as, for example, 'walk' and 'run' (cf. Wong et al., to appear): one can walk backwards but one cannot *walk forwards, because the notion of 'front' is inherent in the concept of 'walking' itself.

Thus, in addition to lexico-semantic universals of the human body such as 'body' and 'hands', and universal principles of organization such as partonomy, hierarchy, duality, "topography" and "internal logic", I would add one further universal: the body's inherent "orientation", its conceptual division into "front" and "back", and consequently, its status as potential reference point (alongside external reference points such as the sun or some features of local topography) for human orientation in space.

\section{The human body as a conceptual frame of reference}

In an essay published in 1768, Kant affirmed that "in physical space, on account of its three dimensions, we can conceive three planes which intersect one another at right angles", and that the human body is conceived as lying at the intersection of these planes.

The plane to which the length of our body stands perpendicular is called, in reference to us, horizontal; it gives rise to the distinctions of the regions we indicate by above and below. Two other planes (...) can stand perpendicular to the horizontal plane, in such a manner that the length of the human body is conceived as lying in the line of their intersection. One of these vertical planes divides the body into two outwardly similar parts and supplies the ground for the distinction between right and left; the other which is perpendicular to it, makes it possible for us to have the concepts of before and behind. (Kant 1991[1768], pp. 28-29)

Kant's description of the human body as conceptualized in terms of three planes is consonant with the semantic universals emerging from the present study: as argued here, the head is conceived of as being ABOVE all the other parts of the body and the legs, as being BELOW all the other parts; arms and hands are conceived of as being ON TWO SIDES OF the body; the chest and belly are conceived of as being on the FRONT ("before") side of the body, and the back and backside, as being on the BACK ("behind") side of the body. 
As Bryant et al. (1992, p. 97) put it, the human body provides, in this way, a "spatial framework" for our orientation in the world and our interpretation of the world:

A spatial framework forms a mental scaffolding on which specific information can be arranged and rearranged, information drawn from the world or from discourse about the world. For the internal spatial framework, the scaffolding is formed from the observer's body axes and for the external framework from a set of axes projected from the observer.

In their well-known polemical article entitled "Immanuel Kant among the Tenejapans: Anthropology as empirical philosophy", Levinson and Brown (1994) focused their attention on Kant's mention of the words 'right' and 'left' in the passage quoted above, and pointing out that these words were not universal argued that Kant's overall account was misguided.

But in fact the words 'right' and 'left' were not central to Kant's conception at all. What mattered most to him were the three axes: 1. above and below, 2. two sides of the body (those where people's arms/hands are), and 3. front and back. The semantic universals of body-part nomenclature arising from the present study support the importance of these three axes. They also support the view that these three axes matter in the conceptual organization of the space around the body - a point that Levinson and his colleagues have disputed in numerous publications over the last 15 years or so.

The fact that the body is seen as having a vertical axis is manifested in the semantic opposition between the head ("above all the other parts of the body") and the legs ("below all the other parts of the body"). It also fits in with the important role of the opposites ABOVE and BELOW in numerous body-part concepts: 'chest' (above) and 'belly' (below), 'back' (above) and 'backside' (below), 'forehead' (above) and 'chin' (below), and so on.

This concept of the "verticality" of the body explains why the standing posture is treated in many languages as more basic than the lying one. For example, it explains why in English a newborn baby can be described as " $50 \mathrm{~cm}$ long" whereas an adult cannot be described as "1.70 cm long" (cf. Wierzbicka, 2006a). More generally, it explains the crucial role of the concepts ABOVE and BELOW in the semantics of "posture verbs" like 'stand', 'sit' and 'lie', that is to say, in the habitual interpretation of these postures reflected in the world's languages (cf. Newman, 2002), and, through extended uses of posture verbs, in the interpretation of the position and location of various objects in the world around us (objects that "stand" or "lie" somewhere, and in English even "sit"; cf. Wierzbicka, 2006a).

The fact that the body is seen as having two symmetrical sides, defined by the position of the arms "on two sides of the body" (i.e., "right" and "left"), supplies the ground for distinctions like that between a "wide path" and a "narrow path" (what matters is, roughly speaking, how much room one has on either side of the body).

The fact that the body is seen as having two asymmetrical sides, the front and the back, supplies the ground for notions like 'going straight ahead', 'going forward', and even for physical activity concepts like 'walk' and 'run' (cf. Wong et al., to appear).

Disputing the universal significance of Kant's "three axes" to the "naïve" human conception of the world, Levinson and Brown (1994, p. 32) contrasted a "Kantian world" with a "Leibnizian world", more compatible in their view with the facts from languages like Tzeltal:

...the Tzeltal facts point to a different conclusion. We can happily dispense with left/ right as the basis of the third plane in our naïve conception of abstract space. (...) 
You can live consistently in a Leibnizian world, with space thought of merely as a network of positions, provided you (...) stick firmly to the idea that a left hand and a right hand have just the same shape.

But can human beings really live in a "Leibnizian world", devoid of any body-centric perspective altogether? After all, for normal human beings, what matters is not "abstract space", but the concrete place where they are: the scene in front of them, the ground under their feet, the objects on both sides of their body.

Granted, the body-centric perspective on the world does seem to be more prominent in some languages than in others (as documented by Levinson and his colleagues), and such differences are indeed significant. But to conclude from this that some human groups live in a "Kantian world" and others in a "Leibnizian world" is surely going too far.

The universals of body-part semantics may or may not include the concepts of 'right hand' and 'left hand', but they do include word-meanings with the component "on two sides of the body" ('hands', 'arms'). They also include concepts broadly comparable to 'chest' and 'back', that is, to Kant's "before" (front) and "behind" (back).

To orient ourselves in the place where we are we need, first of all, to see what is in front of us. We also need to see the ground under our feet and to take note of what can be seen, and what is going on, on both sides of our body (those where the arms are). These are the three "planes" that Kant was talking about. The universals of the semantic field of the human body reflect the importance of these three planes.

We do not live, then, in a "Leibnizian world", "with space thought of merely as a network of positions", but in a world in which, as Bryant et al. (1992, p. 97) put it, paraphrasing Kant, "the space is (...) organized around the body rather than around other referents in space". We also live in a world which we interpret through the prism of shape concepts like 'long', 'round' and 'flat' - all based on the concept 'hands', and physical property concepts like 'hard', 'soft' and 'sharp', which (as shown in Goddard and Wierzbicka, in press) are also based on 'hands'.

Human orientation in the world depends to a very large extent on sight and touch, that it, on our eyes and hands. What people touch is, above all, the things in their hands and the things in front of them; and what they see is, above all, what is in front of them. The concepts of 'hands' and 'eyes' are vital to human language and cognition, and the semantic universals of body-part terminology, which differentiate between the front and the back of the body, and privilege the front, reflect this.

As I argued in Lexicography and Conceptual Analysis, the conceptual world we live in is very much a body-centric world. Not "we Anglos" or "we Westerners", but "we humans". Not only does 'body' appear to be a genuinely universal human concept, but the basic categorization and interpretation of the body appears to be very much the same in all languages. The body is not just a "physical universal" (as the Introduction to the Special Issue calls it), it is almost certainly a conceptual universal. It is also a shared human yardstick for interpreting the world.

\section{A coda: a conceptual approach to semantic typology and language universals}

Forty five years ago, just a few years before his untimely death, Uriel Weinreich, a pioneer and champion of semantics in the virulently anti-semantic Harrisean and Chomskyan era, wrote a "Draft Proposal: on the semantic structure of natural language". Pointing out 
that "the study of semantic aspects of language has fallen far behind the investigation of its grammatical and phonological dimensions" (1980, p. 389), Weinreich argued that there was no reason why the semantic structure of language could not be studied as such:

Since the main purpose of speech is meaningful communication, there is hardly a more significant study than the clarification of how the coding of meanings takes place within the limitations of phonological and grammatical structure. For the problem to be amenable to scientific analysis, it is necessary to operate, not with intuitive notions of meanings, but with explicit, verbalized, validated meaningdescriptions. The significance of the project lies in its search for a satisfactory methodology for obtaining and evaluating such meaning-descriptions. It is to be noted that the stress is not on words as responses to the physical stimuli of which they are "names", but in those interrelations of words which display their covert semantic structures. (Emphasis in italics in the original, emphasis in bold added)

Words like "responses" and "stimuli" are no longer in vogue in linguistics but the kind of "semantics without semantics" that one sees, for example, in the Special Issue (or, for that matter, in much of contemporary colour research based on Munsell chips) is in fact far more about "responses to physical stimuli" than about "meaning-descriptions". It is ironic that words like "cognitive" and "conceptualization" are so frequently used today by authors who are clearly more interested in "responses to physical stimuli" than in any genuine investigation of indigenous meanings. ${ }^{13}$

For Weinreich, the heart of semantics lied in "explicit, verbalized, validated meaningdescriptions" and the key task was to "search for a satisfactory methodology for obtaining and validating such meaning-descriptions". This is why the present study, which is focused on explicit, verbalized, validated meaning-descriptions, and on a suitable methodology for obtaining such descriptions, is dedicated to the memory of Uriel Weinreich.

It is not my purpose here to discuss the affinities (as well as the differences) between Weinreich's program for semantics and the NSM-based research, but let me adduce three more short quotes from Weinreich's "Draft Proposal”' (1980, p. 386), crucial, in my view, for semantic typology:

1. To avoid the danger of bias due to concentration on a single language, each study will consider materials from several languages other than English.

2. In every case, the investigator's "best" analysis, or several alternative analyses, will be validated by testing their acceptability to representative native speakers of the language.

3. Native speakers of various languages, of various ages and degrees of literacy, will be given tasks involving the verbalization of meanings and the evaluation of alternative definitions of well-known words. This will throw light on the validity of lexicographic definitions as an approximation of lay speakers" "intuitions" concerning the meanings of words in their language.

\footnotetext{
${ }^{13}$ For a rare semantic study of body-part terms which does produce a large set of meaning-descriptions, see Arbatchewsky-Jumarie and Iordanskaja (1988). The human body is also the topic of a very detailed contrastive (Russian vs. English) study by Iordanskaja and Paperno (1996). While the focus of this work is collocational, the observations made by the authors are highly pertinent to any in-depth study of the conceptualization of body parts in Russian and in English.
} 
The NSM approach to semantic typology, which seeks to formulate meaning-descriptions in a "natural semantic metalanguage" intelligible to ordinary native speakers ("lay speakers"), makes it possible to implement Weinreich's program.

Deploring (in 1966) the virtual non-existence of serious, methodologically informed studies into semantic typology and semantic universals and referring to the semantic theories available at that time, Weinreich wrote (1966, p. 144):

There exists a fatal abyss between semantic theory and semantic description (Weinreich, 1962, 1980), an abyss which dooms the former to emptiness and the latter to atomization. Subtle philosophers of language like Cassirer (1923) have indiscriminately mixed reliable and unreliable evidence about languages, sometimes allowing evolutionary prejudices to come into play; brilliant logicians have shown a lack of curiosity about languages other than their own.

His conclusion was: "Almost everything still remains to be done".

I dedicate this study to the memory of Uriel Weinreich ${ }^{14}$ in the conviction that in the course of the intervening 40 years something has been done, and also, that 40 years on, we have developed an effective methodology for studying semantic structures, which can be offered as a reliable guide to anyone interested in pursuing cross-linguistic semantics and semantic typology and in a search for universals of human language and cognition.

\section{References}

Ameka, F., 1994. Ewe. In: Goddard, C., Wierzbicka, A. (Eds.), pp. 57-86.

Andersen, Elaine S., 1978. Lexical universals of body-part terminology. In: Greenberg, Joseph H. (Ed.), Universals of Human Language, Word Structure, vol. 3. Stanford University Press, Stanford, pp. 335-368.

Apresjan, Yurij, 1991. Lexical Semantics. Karoma, Ann Arbor, MI.

Apresjan, Yurij, 2000. Systematic Lexicography. Oxford University Press, Oxford.

Arbatchewsky-Jumarie, Nadia, Iordanskaja, Lidija, 1988. Le champ lexical 'Parties du corps': description sémantique des lexemes et structure des vocables. In: Mel'čuk, Igor (Ed.), Dictionnaire Explicatif et Combinatoire du Français Contemporain. Les Presses de l'Université de Montréal, Montréal.

Bain, Margaret, 1992. The Aboriginal-White Encounter in Australia: Towards Better Communication. Summer Institute of Linguistics, Darwin.

Boas, Franz, 1938. The Mind of Primitive Man, Rev. edn. Macmillian, New York.

Brown, Cecil H., 1976. General principles of human anatomical partonomy and speculations on the growth of partonomic nomenclature. American Ethnologist 3, 400-424.

Brotherson, A., in press. The ethnogeometry of Makasai. In: Goddard, C. (Ed.), Cross-Linguistic Semantics. John Benjamins, Amsterdam.

Bryant, D.J., Tversky, B., Franklin, N., 1992. Internal and external spatial frameworks for representing described scenes. Journal of Memory and Language 31, 74-98.

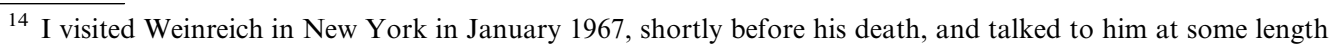
about the program of semantic research based on universal semantic primes which my Polish colleague Andrzej Bogusławski and I had been engaged in since 1964. Weinreich, who had written a very appreciative account of Russian lexicology for Volume I of Current Trends in Linguistics, saw our program, too, as highly germane to his own vision for semantics, and he gave me strong encouragement, which I would like to acknowledge with gratitude.
} 
Bugenhagen, R.D., 1994. The exponents of semantic primitives in Mangap-Mbula. In: Goddard, C., Wierzbicka, A. (Eds.), Semantic and Lexical Universals: Theory and Empirical Findings. John Benjamins, Amsterdam, pp. 87-108.

Bugenhagen, R.D., 2002. The syntax of semantic primitives in Mangaaba-Mbula. In: Goddard, C., Wierzbicka, A. (Eds.), Meaning and Universal Grammar: Theory and Empirical Findings. vol. II. John Benjamins, Amsterdam, pp. 1-64.

Burenhult, N., 2006. Body part terms in Jahai. In: Majid et al. (Eds.), Parts of the body: Cross-Linguistic Categorisation. Language Sciences 28 (2-3), 162-180 (Special Issue).

Cassirer, E., 1923. Philosophie der Symbolischen Formen. Berlin (English edition: New Haven, 1953).

Chappell, H., 1994. Mandarin Semantic Primitives. In: Goddard, C., Wierzbicka, A. (Eds.), pp. 109-147.

Chappell, Hilary., 2002. The universal syntax of semantic primes in Mandarin Chinese. In: Goddard, C., Wierzbicka, A. (Eds.), Meaning and Universal Grammar: Theory and Empirical Findings. vol. I, John Benjamins, Amsterdam, pp. 243-322.

Chappell, Hilary, McGregor, William (Eds.), 2002. The Grammar of Inalienability: A Typological Perspective on Body Part Terms and the Part-Whole Relation. Mouton de Gruyter, Berlin.

Diller, A., 1994. Thai. In: Goddard, C., Wierzbicka, A. (Eds.), Semantic and Lexical Universals: Theory and Empirical Findings. John Benjamins, Amsterdam, pp. 149-170.

Durie, Mark, Daud, Bukhari, Hasan, Mawardi, 1994. Acehnese. In: Goddard, C., Wierzbicka, A. (Eds.), pp. 171-202.

Dyen, Isidore, James, A.T., Cole, J.W.L., 1967. Language divergence and estimated retention rate. Language 43, $150-171$.

Enfield, N.J., 2002. Combinatoric properties of natural semantic metalanguage expressions in Lao. In: Goddard, C., Wierzbicka, A. (Eds.), Meaning and Universal Grammar: Theory and Empirical Findings. Vol. II. John Benjamins, Amsterdam, pp. 145-256.

Enfield, N.J., 2006a. Elicitation guide of parts of the body. In: Majid et al. (Eds.), Parts of the body: CrossLinguistic Categorisation. Language Sciences 28 (2-3) 148-156 (Special Issue).

Enfield, N.J., 2006b. Lao body part terms. In: Majid et al. (Eds.), pp. 181-200.

Enfield, N.J., Majid, Asifa, van Staden, Miriam, 2006. Cross-linguistic categorisation of the body: Introduction. In: Majid et al. (Eds.), Parts of the body: Cross-Linguistic Categorisation. Language Sciences 28 (2-3) 137147 (Special Issue).

Evans, N., 1994. Kayardild. In: Goddard, C., Wierzbicka, A. (Eds.), pp. 203-228.

Evans, N., 1996. The syntax and semantics of body part incorporation in Mayali. In: Chappell, Hilary and McGregor, William (Eds.), The Grammar of Inalienability: A Typological Perspective on Body Part Terms and the Part-whole Relation. Mouton de Gruyter, Berlin, pp. 65-110.

Evans, N., Wilkins, D.P., 2001. The complete person: networking the physical and the social. In: Simpson, J., Nash, D., Laughren, M., Austin, P., Alpher, B. (Eds.), Forty Years on: Ken Hale and Australian Languages. Pacific Linguistics 512, 493-521.

Friedrich, Paul, 1970. Shape in Grammer. Language 46, 379-407. Reprinted in Paul Friedrich 1979. Language, Context, and the Imagination. Stanford, California: Stanford University Press, pp. 340-359.

Foley, William A., 1997. Anthropological Linguistics: An introduction. Blackwell Publishers, Oxford.

Gaby, A.R., 2006. The Thaayorre 'true man': Lexicon of the human body in an Australian language. In: Majid et al. (Eds.), Parts of the body: Cross-Linguistic Categorisation. Language Sciences 28 (2-3) 201-220 (Special Issue).

Goddard, C., 1989. Issues in Natural Semantic Metalanguage. Quaderni di semantica 10/1, 51-64.

Goddard, C., 1994. Lexical primitives in Yankunytjatjara. In: Goddard, C., Wierzbicka, A. (Eds.), pp. 229-262.

Goddard, C., 1998. Semantic Analysis: A Practical Introduction. Oxford University Press, Oxford.

Goddard, C., 2000. Polysemy: A Problem of Definition. In: Ravin, Yael, Leacock, Claudia (Eds.), Polysemy and Ambiguity: Theoretical and Applied Approaches. Oxford University Press, pp. 129-151.

Goddard, C., 2001. Lexico-semantic universals: A critical overview. Linguistic Typology. 5, 1-65.

Goddard, C., 2002a. The search for the shared semantic core of all languages. In: Goddard, C., Wierzbicka, A. (Eds.), Meaning and Universal Grammar: Theory and Empirical Findings. Vol. II. John Benjamins, Amsterdam, pp. 5-40.

Goddard, C., 2002b. Semantic primes and universal grammar in Malay (Bahasa Melayu). In: Goddard, C., Wierzbicka, A. (Eds.), Meaning and Universal Grammar: Theory and Empirical Findings. Vol. II. John Benjamins, Amsterdam, pp. 87-172. 
Goddard, C., 2006. Natural semantic metalanguage. In: Brown, K. (Ed.), Encyclopedia of Language and Linguistics, second ed., pp. 544-551.

Goddard, C., in press-a. Semantic primes and conceptual ontology. In: Zaefferer, D., Schalley, A. (Eds.), Ontolinguistics: How Ontological Status Shapes the Linguistic Coding of Concepts.

Goddard, C., in press-b. Contrastive semantics and cultural psychology: English heart vs. Malay hati.

Goddard, C., Wierzbicka, A., in press. NSM analyses of the semantics of physical properties: sweet, hot, hard, heavy, rough, sharp in cross-linguistic perspective. Studies in Language.

Goddard, C., Wierzbicka, A., 1994a. Introducing lexical primitives. In: Goddard, C., Wierzbicka, A. (Eds.), Semantic and Lexical Universals: Theory and Empirical Findings. John Benjamins, Amsterdam, pp. 31-56.

Goddard, C., Wierzbicka, A. (Eds.), 1994b. Semantic and Lexical Universals: Theory and Empirical Findings. John Benjamins, Amsterdam.

Goddard, C., Wierzbicka, A. (Eds.), 2002. Meaning and Universal Grammar: Theory and Empirical Findings, 2 vols. John Benjamins, Amsterdam.

Goddard, C., Karlsson, S., 2004. Re-thinking 'think': Contrastive semantics of Swedish and English. In: Proceedings of the 2003 Conference of the Australian Linguistic Society. Available from: <http:// www.newcastle.edu.au/school/lang-media/news/als2003/>.

Goodnow, J., 1977. Children Drawing. Harvard University Press, Cambridge, MA.

Hale, Ken, 1994. Preliminary observations on lexical and semantic primitives in the Misumalpan languages of Nicaragua. In: Goddard, C., Wierzbicka, A. (Eds.), pp. 263-284.

Hallpike, Christopher Robert, 1979. The Foundations of Primitive Thought. Clarendon, Oxford.

Harkins, Jean, Wilkins, David P., 1994. Mparntwe and the search for lexical universals. In: Goddard, C., Wierzbicka, A. (Eds.), Semantic and Lexical Universals: Theory and Empirical Findings. John Benjamins, Amsterdam, pp. 285-310.

Haviland, John, 1979. Guugu Yimidhirr. In: Dixon, R.M.W., Blake, Barry (Eds.), Handbook of Australian Languages, I. ANU Press, Canberra, pp. 27-180.

Henderson, John, Dobson, Veronica, 1994. Eastern and Central Arrernte to English Dictionary. IAD Press, Alice Springs.

Hill, D., 1994. Longgu. In: Goddard, C., Wierzbicka, A. (Eds.), Semantic and Lexical Universals: Theory and Empirical Findings. John Benjamins, Amsterdam, pp. 311-330.

Iordanskaja, Lidia, Paperno, Slava, 1996. A Russian-English Collocational Dictionary of the Human Body. Slavica Publishers, Columbus.

Junker, Marie-Odile, 2003. A Native American view of the "mind" as seen in the lexicon of cognition in East Cree. Cognitive Linguistics 14 (2-3), 167-194.

Junker, Marie-Odile, Blacksmith, Louise, 2006. Are there emotional universals? Evidence from the Native American language East Cree. Culture \& Psychology 3 (12), 275-304.

Kant, I., 1991. Von dem Ersten Grunde des Unterschiedes der Gegenden im Raume (Translation 'On the First Ground of the Distinction of Regions in Space'). In: van Cleve, J., Frederick, R.E. (Eds.), The Philosophy of Right and Left. Kluwer, Dordrecht, pp. 27-33.

Keesing, Roger M., 1994. Radical cultural difference: Anthropology's myth? In: Pütz, Martin (Ed.), Language Contact and Language Conflict. Benjamins, Amsterdam, pp. 3-24.

Kellogg, R., 1969. Analyzing children's art. National Press, Palo Alto.

Langacker, Ronald, 1990. Concept, Image, and Symbol: The Cognitive Basis of Grammar. Mouton de Gruyter, Berlin.

Levinson, Stephen C., 1996. Language and Space. Annual Review of Anthropology. 25, 353-382.

Levinson, Stephen C., 2006. Parts of the body in Yélî Dnye, the Papuan language of Rossel Island. In: Majid et al. (Eds.), Parts of the body: Cross-Linguistic Categorisation. Language Sciences 28 (2-3) 221-240 (Special Issue).

Levinson, Stephen C., Brown, Penelope, 1994. Immanuel Kant among the Tenejapans: Anthropology as empirical philosophy. Ethos. 22, 3-41.

Lewis, Gilbert, 1974. Gnau anatomy and vocabulary for illness. Oceania. 45, 50-78.

Lyons, John, 1977. Semantics. Cambridge University Press, Cambridge.

Majid, A., Enfield, N.J., van Staden, M. (Eds.), 2006. Parts of the body: Cross-Linguistic Categorisation. Language Sciences 28 (2-3), 137-360 (Special Issue).

Meira, S., 2006. Tiriyó body part terms. In: Majid et al. (Eds.), Parts of the body: Cross-Linguistic Categorisation. Language Sciences 28 (2-3) 262-279 (Special Issue). 
Morrison, Julie, Tversky, Barbara, 2005. Bodies and their parts. Memory and Cognition. 33 (4), 696-709.

Newman, John (Ed.), 2002. The Linguistics of Sitting, Standing, and Lying. John Benjamins, Amsterdam.

Onishi, M., 1994. Semantic primitives in Japanese. In: Goddard, C., Wierzbicka, A. (Eds.), Semantic and Lexical Universals: Theory and Empirical Findings. John Benjamins, Amsterdam, pp. 361-386.

Pawley, A., 1997. The Trans New Guinea Phylum hypothesis: a reassessment. Unpublished manuscript. Australian National University.

Peeters, Bert (Ed.), in press. Semantic Primes and Universal Grammar: Empirical findings from the Romance languages. John Benjamins, Amsterdam.

Ravin, Yael, Leacock, Claudia (Eds.), 2000. Polysemy: Theoretical and Computational Approaches. Oxford University Press, Oxford.

SJP 1958-1969. Słownik Języka polskiego. In: Doroszewski, W. (Ed.), 11 vols. Warsaw: PWN (1958-1969).

van Staden, M., 2006. The body and its parts in Tidore, a Papuan language of Eastern Indonesia. In: Majid et al. (Eds.), Parts of the body: Cross-Linguistic Categorisation. Language Sciences 28 (2-3) 323-343 (Special Issue).

Terrill, A., 2006. Body part terms in Lavukaleve, a Papuan language of the Solomon Islands. In: Majid et al. (Eds.), Parts of the body: Cross-Linguistic Categorisation. Language Sciences 28 (2-3) 304-322 (Special Issue).

Travis, C., 2002. La metalengua semántica natural: the natural semantic metalanguage of Spanish. In: Goddard, C., Wierzbicka, A. (Eds.), Meaning and Universal Grammar: Theory and Empirical Findings. Vol. II. John Benjamins, Amsterdam, pp. 173-242.

Weinreich, Uriel, 1966. On the semantic structure of languages. In: Greenberg, Joseph (Ed.), Universals of Language. The MIT Press, Cambridge, MA.

Weinreich, Uriel, 1980. On Semantics. University of Pennsylvania Press, Philadelphia.

Wierzbicka, A., 1972. Semantic Primitives. Athenäum, Frankfurt.

Wierzbicka, A., 1979. Ethnosyntax and the philosophy of grammar. Studies in Language 3 (3), 313-383.

Wierzbicka, A., 1980. Lingua Mentalis: The Semantics of Natural Language. Academic Press, Sydney.

Wierzbicka, A., 1985. Lexicography and Conceptual Analysis. Karoma, Ann Arbor.

Wierzbicka, A., 1988. Semantics of Grammar. John Benjamins, Amsterdam.

Wierzbicka, A., 1994. Semantic primitives across languages: a critical review. In: Goddard, C., Wierzbicka, A. (Eds.), Semantic and Lexical Universals: Theory and Empirical Findings. John Benjamins, Amsterdam, pp. 445-500.

Wierzbicka, A., 1996. Semantics: Primes and Universals. Oxford University Press, Oxford.

Wierzbicka, A., 1999. Emotions Across Languages and Cultures: Diversity and Universals. Cambridge University Press, Cambridge.

Wierzbicka, A., 2002. Semantic primes and universal grammar in Polish. In: Goddard, C., Wierzbicka, A. (Eds.), Meaning and Universal Grammar: Theory and Empirical Findings. Vol. II. John Benjamins, Amsterdam, pp. 65-144.

Wierzbicka, A., 2003. Empirically established universals of language and their importance for cognitive science. In: Plenary Lecture for the International Cognitive Science Conference, Sydney.

Wierzbicka, A., 2004. Shape and colour in language and thought. In: Plenary Talk for ILCC 2004: International Language \& Cognition Conference, Coffs Harbour.

Wierzbicka, A., 2005. Empirical universals of language as a basis for the study of other human universals and as a tool for exploring cultural differences. Ethos. 33 (2), 256-291.

Wierzbicka, A., 2006a. Shape in grammar revisited. Studies in Language. 30 (1), 115-177.

Wierzbicka, A., 2006b. English: Meaning and Culture. Oxford University Press, New York.

Wierzbicka, A., in press-a. Shape and colour in language and thought. In: Schalley, A., Khlentoz, D. (Eds.), Categorisation, Mental States and Development. John Benjamins, Amsterdam.

Wierzbicka, A., in press-b. Mental lexicon. HSK (Handbücher zur Sprach- und Kommunikationswissenschaft. Handbook of Linguistics and Communication Science.) Slavic Languages. Berlin Mouton de Gruyter.

Wilkins, David, 1996a. Natural tendencies of semantic change and the search for cognates. In: Durie, Mark, Ross, Malcolm (Eds.), The Comparative Method Reviewed. Oxford University Press, New York, pp. 264 304.

Wilkins, D., 1996b. Does 'tyerrtye' mean 'person'? Issues in the exploration of meaning, use and word-relations. Paper presented at Max Planck Institute for Psycholinguistics, Nijmegen.

Wong, Jock, Goddard, C., Wierzbicka, A., to appear. Walking and running: the semantics of human "locomotion". 
Yoon, K.-J., 2004. Korean maum vs. English heart and mind: Contrastive semantics of cultural concepts. In: Proceedings of the 2003 Conference of the Australian Linguistic Society. Available from: <http:// www.newcastle.edu.au/school/lang-media/news/als2003/proceedings $>$.

Yoon, Kyung-Joo, 2006. Constructing a Korean Natural Semantic Metalanguage. Hankook Publishing Company, Seoul. 